\title{
COLEÇÃO WILLIAM LIPKIND DO MUSEU NACIONAL: TRILHAS ANTROPOLÓGICAS BRASIL-ESTADOS UNIDOS*
}

Manuel Ferreira Lima Filho

1. Uma coleção atravessou meu caminho...

Entre os anos de 2009 a 2011, voltei a fazer etnografia entre os Karajá. Haviam se passado mais de 20 anos após ter realizado uma pesquisa de campo que totalizou seis meses e teve por objetivo etnografar o rito de iniciação masculina denominado Hetohokỹ (Lima Filho 1994). Agora, eu retornava para compor a equipe com o intuito de construir um dossiê escrito e produzir dois documentários fílmicos, a fim de constituir o processo de registro das bonecas karajá - ritxòò como patrimônio cultural imaterial brasileiro (Lima Filho et al. 2011a, 2011b, 2011c).

Quando da realização dos estudos sobre as bonecas karajá, fui convidado pelo curador da Seção de Etnologia e Etnografia do Museu Nacional (UFRJ), o antropólogo João Pacheco de Oliveira Filho, a colaborar com a identificação de artefatos que fariam parte da exposição "Plumária Karajá" (2012) em homenagem à Maria Heloísa Fénelon Costa, que foi curadora das coleções do Museu Nacional por vários anos e realizou importante pesquisa sobre a arte karajá, de modo especial as bonecas de cerâmica. Desse modo, três objetos foram reconhecidos por Isarire Karajá.

Isarire é filho de Maluaré, que era xamã e chefe dos rituais e exerceu papel importante na década de 1940-1960 quando os Karajá e a ilha do Bananal foram ícones simbólicos da Marcha para o Oeste nos governos de Getúlio Vargas e Juscelino Kubitschek (Lima Filho 1994). Isarire é servidor da Funai, técnico agrícola e um intelectual do grupo. Ele é membro da rede de parentes da família extensa de Maluaré, na qual me inseri na pesquisa de campo na década de 1980.

Entre os objetos identificados por Isarire havia um saiote de plumária de ema, de uso dos viúvos nos rituais. O saiote havia sido coletado por William Lipkind, antropólogo estadunidense que fez pesquisa de campo no rio Araguaia nos anos de 1938 e 1939. 
Figura 01 - N. Identificação - 28.634 - Saiote emplumado confeccionado com faixa de fios de algodão tecida com três listras horizontais em marrom. Compõe fieira de penas com corte horizontal nas cores branco e preto.
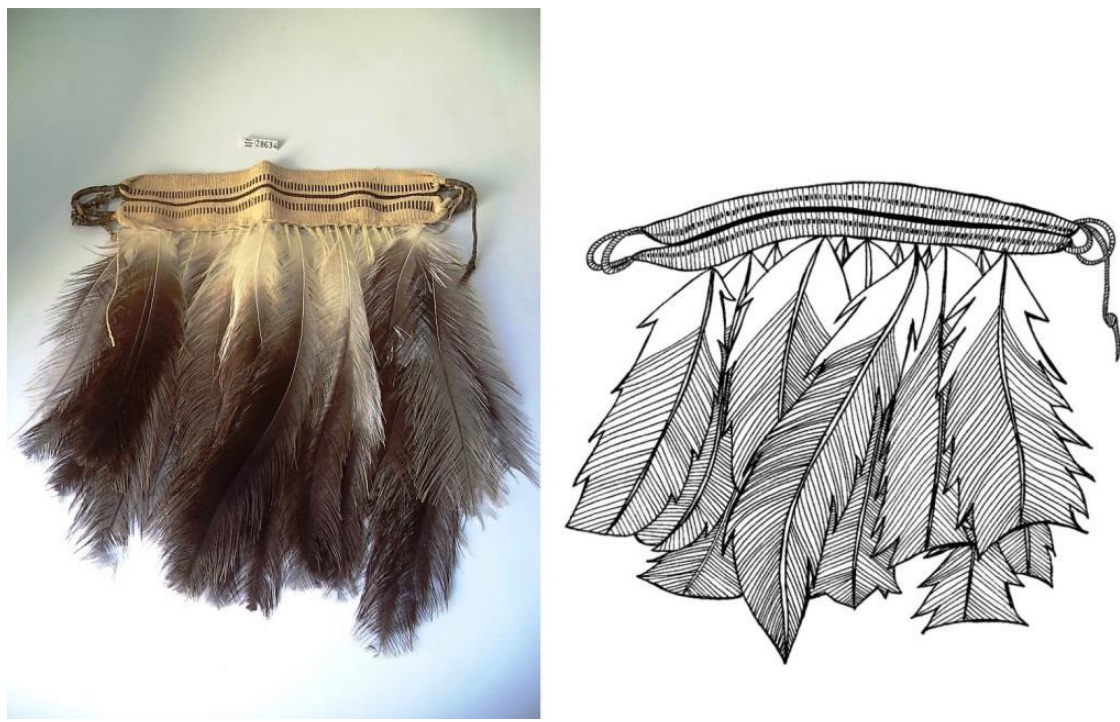

Cecília Ewbank (2015), desenho de Pedro A. S. Henrique.

A surpresa pela existência de uma coleção no Museu Nacional realizada por Lipkind se justificava, pois as etnografias dos Karajá não fazem referências a ela (Donahue,1982; Toral,1992; Rodrigues, 1993, 2008; Petesch, 1993, 1996), e nem mesmo o próprio Lipkind $(1940,1948)$. A única exceção foi Edna Taveira, que analisou nove exemplares da coleção na etnografia que fez sobre a cesta karajá (Taveira 2013: 177, 178).

O fato chamou a minha atenção porque as coleções karajá confiáveis, mais recuadas no tempo, foram realizadas pelos alemães Paul Ehrenreich (1948), em 1888, e Fritz Krause (1940/43), em 1904. A respeito dessas coleções sabe-se que a de Krause se encontra no então Museu de Leipzig, hoje Grassi für Völkerkunde zu Leipzig, Alemanha. Posteriormente, outras coleções karajá passaram a compor as reservas técnicas e as exposições de museus nacionais e internacionais. ${ }^{1}$ 
O reencontro com os Karajá, centrado no tema da fabricação, do uso social e político de suas bonecas de cerâmicas (ritxòò), ${ }^{2}$ e o primeiro contato com a coleção de William Lipkind incentivaram-me a pesquisar os bastidores da coleção, como as trocas de cartas entre Heloísa Alberto Torres, Herbet Baldus, Charles Wagley, Buell Quain, Ruth Landes, Franz Boas, Ruth Benedict e as correspondências de William Lipkind. ${ }^{3}$

A motivação da pesquisa foi buscar conexões entre os itinerários dos atores e personagens relacionados à constituição da coleção, que pudessem revelar as representações sobre o desenvolvimento da antropologia enquanto disciplina nos Estados Unidos (Stocking 2004) e no Brasil, tendo os Karajá - seus saberes e fazeres - como empreitada antropológica inspirada pelo culturalismo.

Do ponto de vista metodológico, à maneira de Stocking Jr. (1982), evitei fazer um julgamento das atitudes de Lipkind e dos atores sociais presentes na rede formada pelas trilhas que ele percorreu, tendo a construção da coleção como fato social e o contexto histórico no qual estava situado o antropólogo. Contudo, não deixei de lançar um olhar crítico, de colocar sob suspeição práticas antropológicas impregnadas de colonialismo e concordando que do ponto de vista sociológico não há ato desinteressado, como escreveu Bordieu (1996a). Nesta perspectiva, o passado (cartas, memorandos, fotografias, telegramas, depoimentos) foi alvo de uma interpretação e, por isso, é igualmente uma leitura contemporânea, sempre renovada, como sugere Jacques Le Goff (1991).

A opção de seguir ao longo dos anos os movimentos biográficos de William Lipkind, como filiação, períodos formativos, deslocamentos entre o Brasil, os Estados Unidos e Europa, não tem a intenção de construir uma ilusão biográfica, como advertiu Bordieu, mas de situar o tempo e o espaço na perspectiva de uma experiência histórica inserida "num processo não imutável da interiorização do social e da incorporação de uma persona social" (Montagner 2007:240), estando em jogo vetores como: inscrição de regras familiares, classe, identidade étnica, estigma, situação econômica, geopolítica mundial, inserção no mercado de trabalho, e representações no caso do ofício da antropologia e suas conexões políticas (colonialismo, ética, produção e controle da alteridade). Os arranjos desses vetores não isentos de conflitos, tensões, deslocamentos, frustrações e até dissimulações que atravessam a biografia de Lipkind devem ser lidos na inspiração bourdieusiana de jogo de forças, que desenham a formação do campo intelectual antropológico no Brasil e nos Estados Unidos em tempos ansiosos de uma antropologia por se fazer "ciência". E a construção de uma coleção de artefatos karajá é o outro fio condutor que ajudará a compreender os contornos do referido campo em seus momentos formativos. 


\section{Os itinerários de William Lipkind}

\subsection{Os Lipkind aportam em New York}

William Lipkind nasceu em New York em 17 de dezembro de 1904. Era filho de emigrantes judeus-russos. O pai, que se chamava Marx A. Lipkind, era natural de Minsk, Rússia, nascido em 1881. O jovem emigrante tinha 16 anos quando aportou nos Estados Unidos em 1897 e depois se tornou médico. A mãe de William Lipkind era conhecida como Bessi. ${ }^{4}$ Nasceu na Rússia em 1884 e onze anos mais tarde migrou para os Estados Unidos, em 1895. De fato, o nordeste dos Estados Unido recebeu nas últimas décadas do século 19 várias levas de emigrantes. No ano de 1920, por exemplo, os Lipkind estavam presentes, por ordem de ocupação, nos estados de Massachusetts, New York e Pennsylvania (Ancestry 2014a, 2014b, 2014c, 2014d, 2014m).

A identificação judaica de Lipkind não passará neutra em seus movimentos profissionais. Um ambiente antissemítico, que tomará grandes proporções durante a Segunda Grande Guerra, colocará Lipkind ao lado Ruth Lands. A antropóloga escreve em uma de suas cartas que essa identificação de ambos foi a razão de certo desprezo de Heloísa Alberto Torrres (1895-1977).

Os censos oficiais dos Estados Unidos dos anos de 1910, 1915, 1920 e 1925 registram que o casal morava na cidade de New York. William Lipkind era o filho mais velho. O censo de 1910 cita os nomes dos filhos William, de 5 anos, e de Zehemiah, de 4 anos. No entanto, os censos de 1915, 1920 e 1925 não registram mais o nome de Zehemiah e sim o de Norman, o único nome que aparece como irmão no obituário de William Lipkind no New York Times, em 1974 (Ancestry 2014c, 2014e, 2014f, 2014g, 2014h,2014i).

William Lipkind realizou seus estudos de graduação no City College of New York, colando grau em 1927. Começou seus estudos de pós-graduação em Literatura Inglesa na Columbia University, instituição em que concluiu seu mestrado. Na mesma Universidade cursou o doutorado em Antropologia. Seu primeiro trabalho de campo foi no verão de 1936, quando foi para Nebraska estudar a língua Winnebago, que serviria de base para sua tese de doutorado em 1945, intitulada Winnebago Grammar, publicada no mesmo ano (Columbia University 2014; City College of Ney York 1946; Lipkind 1945).

O gosto pela literatura e a habilidade linguística moverão Lipkind para buscar um lugar como professor de Linguística no Museu Nacional, no Rio de Janeiro, respondendo, num primeiro momento, ao desejo da antropóloga Heloísa Alberto Torres de consolidar os quatro campos da antropologia na instituição da qual havia assumido a direção. 
Havia um acordo informal entre o Museu Nacional do Rio de Janeiro e a Universidade de Columbia para a realização de pesquisas e a formação de etnólogos (Corrêa 1997:12-13).

O intercâmbio entre a Universidade de Columbia e o Museu Nacional atendia a interesses recíprocos. Franz Boas desempenhava um importante papel na demarcação do campo da Antropologia nos Estados Unido, visando consolidá-la enquanto ciência. A formação profissional de estudantes, que ficou conhecida como "quatro campos" ou "four fields", representados pela Linguística, a Antropologia, a Arqueologia e a Antropologia Física, seria uma estratégia para essa consolidação ${ }^{5}$. E como esclarece Charles Wagley, Ralph Linton, que era professor na Universidade de Columbia, já debatia a questão antropológica da aculturação (Wagley 1983:03).

O Brasil era um vasto campo a ser explorado a partir da concepção dos four fields, tanto pelo propósito de fazer "coleções-tipos" dos grupos indígenas como para testar as premissas do culturalismo e constituir o que se pensava na época de uma área etnográfica, no caso os Gê-Tupi no Brasil Central. A noção de área geográfica cultural será retomada mais tarde por David Maybury-Lewis, que coordenará nos anos 60-70, em conjunto com o mesmo Museu Nacional, o "Central Brazil Harvad Project", agora inspirado pelo estruturalismo e o sistema de parentesco, a fim de etnografar os grupos indígenas na região (Maybury-Lewis 1979).

Mas, ao mesmo tempo, se a Antropologia estadunidense alçava velas para outros mundos, os efeitos da Depressão de 1929 inibiam posições de trabalho para os novos antropólogos: "There were few teaching positions available for anthropologists, for it was still the end of the Great Depression [...]", explicou Charles Wagley, um dos estudantes de Columbia que desempenharia um papel esclarecedor na trajetória de Lipkind e no destino de uma coleção karajá que Lipkind pretendia levar para os Estados Unidos (Wagley 1983:03).

A iminência de uma Segunda Grande Guerra também reduzia a possibilidade de ocupação profissional para os novos antropólogos e Heloísa Alberto Torres fez da necessidade da formação de novos antropólogos, fossem eles estadunidenses ou brasileiros, a sua meta mestra enquanto diretora do Museu Nacional, chegando a expor seus planos no encontro que manteve com o presidente Getúlio Vargas (Corrêa 1997:14).

Assim, ao marcarem o campo epistemológico da antropologia da época, Boas e seus estudantes e depois professores como Ruth Benedict e Margareth Mead buscaram novas possibilidades de atuação profissional fora dos Estados Unidos. Intenção que recebeu abrigo institucional no Museu Nacional do Rio de Janeiro, uma vez que se adequava exatamente ao propósito da nova diretora. 
Se o Brasil estava interessado em formar profissionais para desenvolver e consolidar a Etnologia Brasileira, empreitada claramente assumida por Heloísa Alberto Torres no Museu Nacional, Franz Boas, nos Estados Unidos, em 1938, publica o livro Race, Language and Culture (1940), que reúne seus estudos sobre os Kwakiutl, como uma síntese de seus longos anos de estudos tecendo as áreas dos "four fields" e, de modo especial, interessado no processo das mudanças culturais. Assim, os indígenas "isolados" do Brasil Central passam a ser de grande interesse para Boas. Na Universidade de Columbia, ele convence alguns orientandos a fazerem pesquisa no Brasil (Moura 2006). Entre eles estava William Lipkind, que assumiu a chefia da missão de estudos acompanhado por Buell Quain e, mais tarde, por Charles Wagley e Ruth Lands. Houve, pois, uma conjunção de interesses entre Heloísa Alberto Torres e Franz Boas. O primeiro ponto de interseção entre tais interesses foi o povo Karajá do rio Araguaia, que seria estudado por William Lipkind. O Araguaia era um ponto estratégico do ponto de vista etnológico. A sua navegabilidade permitia a inserção dos pesquisadores para alcançar outros grupos. A Oeste, os povos xinguanos; a Leste, os Gê do Tocantins e do Maranhão; ao norte os Tupi, como os Tapirapé.

Lipkind ainda estava envolvido com o doutoramento a respeito do Winnebago quando escreveu para Ruth Benedict sobre o projeto de pesquisa no Brasil: "In the meantime I've selfishly turned my attention to Portuguese and Carajas" (Lipkind 09/09/1937).

\subsection{De Nova York ao interior do Brasil: no meio do caminho havia uma Heloísa}

Mesmo sem concluir seu doutorado, agora com 33 anos, já casado com Maria Cimino (Ancestry 2014l), William Lipkind, é escolhido por Franz Boas e de modo especial por Ruth Benedict para coordenar uma expedição etnológica ao Brasil Central. Ruth Benedict explica as razões da escolha da região:

A Universidade de Columbia tem estado envolvida ativamente por alguns anos em estudos antropológicos na América do Sul. Uma das regiões mais importantes "sobre a qual muito pouco se conhece antropologicamente é a ocupada pelas tribos Gê entre os rios Araguaia e Xingu" (Benedict 04/06/1938).

O interesse de Lipkind pela literatura no mestrado e pela linguística no doutorado encaixava-se no perfil culturalista Boasiano de estudar as línguas indígenas Gê do Brasil Central, então pouco conhecida, como adverte Ruth Benedict na época. Lipkind estava treinado academicamente para coletar a cultura material, incluindo artefatos arqueológicos; mapear dados da estrutura social, sobretudo os mitos e os ritos; e, se possível, integrar informações de antropologia física. 
A permissão para realizar pesquisas etnológicas no país dependia da aprovação do Conselho de Fiscalização das Expedições Artísticas e Científicas do Brasil, que tinha como representante acadêmico a direção do Museu Nacional. O embaixador dos Estados Unidos, em 11 de dezembro de 1937 oficializa a expedição pedindo autorização para o referido Conselho (US Embassy (1937).

Enquanto isso, Heloísa Alberto Torres reunia informações para desenhar o quadro da expedição que pretendia apoiar a fim de colocar seu plano de formação de etnólogos em prática e, ao mesmo tempo, munir o Museu Nacional de coleções etnográficas (Grupione1998; Ewbank 2017). A diretora do Museu escreve para Herbert Baldus, que responde informando sobre a melhor maneira de chegar aos Karajá, os contatos e o que deveria ser levado, em qual das aldeias karajá Lipkind deveria ficar, e sugerindo um plano de etnografia para ser conduzido:

Há três missões protestantes no Araguaya: 1) Adventista em Piedade sob a direção de um alemão de nome Alfredo Straube. 2) O posto principal dos Adventistas em Fontoura sob a direção de um goiano de nome Antão Pereira. 3. Baptista (inglezes) em Macaúba com hospitais de leprosos. O ideal para o sr. Lipkind seria instalar-se em Fontoura que fica 2 léguas acima de Mato Verde, porque o sr. Antão Pereira é, talvez, o melhor conhecedor dos Karajá e, além disso, os adventistas são uma seita americana cujo diretor geral no Brasil é Mr. Wilcox, que reside aqui em São Paulo e pode ser facilmente visitado pelo Sr. Lipkind. O sr. Lipkind, a meu ver, deve concentrar-se no estudo linguístico e, especialmente, tentar conseguir textos de mitos na língua original. Mas para isso precisa morar entre estes índios no mínimo um ano inteiro, precisa de muito amor para com eles e de uma paciência ilimitada. Convém que o sr. Lipkind me visite aqui em São Paulo para que possa dar-lhe mais informações (Baldus 31/12/1937).

No documento da Embaixada Americana, que oficializa a vinda de William Lipkind ao Brasil, fica claro que ele é o chefe da expedição, acompanhado de sua esposa. Buell Quain (1912-1939), então estudante de Doutorado em Columbia, viria como seu assistente.

O documento do embaixador americano foi encaminhado por meio de ofício a Paulo Campos Porto, presidente do Conselho de Fiscalização das Expedições Artísticas e Científicas do Brasil, em 15 de dezembro de 1937. Tal ofício foi assinado pelo secretário geral do Ministério das Relações Exteriores, que confere ao assunto uma "missão diplomática" com caráter de urgência. Paulo Campos Porto despachou do próprio punho: "A informar Heloísa Torres" que, por sua vez recebeu cópia do documento da Embaixada Americana e 
escreveu também do próprio punho: "Sou do parecer que seja concedida a permissão desde que se entreguem ao Governo Brasileiro as duplicatas das peças selecionadas e cópias das fotografias e gravações sonoras, Rio de Janeiro, 19 de janeiro de 1938" (Torres 1938).

Com esse parecer, Paulo Campos Porto respondeu ao Ministério das Relações Exteriores em 29 de janeiro de 1938 que a expedição de William Lipkind tinha sido autorizada e, no documento, explicita que Lipkind, ao sair do país, deveria apresentar para as autoridades brasileiras o certificado de livre saída de sua bagagem, assinado pela autoridade competente e que:

O expedicionário obriga-se a depositar no Museu Nacional do Rio de Janeiro todo o material collectado, onde será examinado por technico designado pelo Conselho de Fiscalização das Expedições Artísticas e Scientíficas no Brasil que resolverá sobre a exportação do mesmo, e a entregar no Museu Nacional do Rio de Janeiro cópias photographicas, gravações e duplicadas das peças colleccionadas (Brasi1 938).

Enquanto Lipkind se organizava para o início da viagem, Buell Quain apresentou em 26 de abril de 1938 um pedido de alteração do seu roteiro com a intenção de estudar os grupos indígenas das nascentes do rio Xingu, e não mais se dirigir ao rio Araguaia. Apesar da resistência do Serviço de Proteção dos Índios (SPI), que preferia que Buell Quain fosse para os Baikari e não para as nascentes do Xingu, a autorização foi concedida e ele viajou ao encontro dos Trumai (Mato Grosso 1938).

William Lipkind manteve o planejado desde Columbia. Em março de 1938 ruma para Anápolis, cidade de Goiás, depois Leopoldina, hoje cidade de Aruanã (GO) e de barco segue pelo rio Araguaia para ilha do Bananal ao encontro dos Karajá.

Maria Cimino, esposa de Lipkind, escreve da aldeia de Fontoura, na ilha do Bananal, em 24 de abril de 1938, para Urbach, irmã de Franz Boas, que morava na cidade do Rio de Janeiro. Na carta informa que haviam chegado à aldeia duas semanas antes (Lipkind 1938). A confirmação do nome da aldeia karajá de Fontoura, como sugeriu Herbet Baldus, e de que William Lipkind fez parte de seu campo acompanhado de sua esposa e, depois outra etapa sozinho também foi publicada numa matéria de domingo de 1940, no estado americano de Nebraska, onde Lipkind estudou a língua Winnebago, enfatizando a expedição de um cientista da civilização para um lugar selvagem: 
A senhora Maria Lipkind, a esposa do explorador, que o acompanhou no sertão durante os primeiros meses de sua expedição e retornou à civilização quando a estação da chuva começou, nunca esquecerá a grande cobra que se arrastou para a cabana em que ela estava tomando banho em Fontoura. Ela gritou por ajuda, o Dr. Lipkind entrou. Felizmente, ele estava carregando seu rifle. Um único tiro restaurou a tranquilidade anterior do banho. A expedição do antropólogo foi incomum na medida em que ele fazia a maior parte de sua exploração sozinho. Ele não teve ajudantes ou carregadores, e ele percorreu milhares de milhas de território desconhecido com apenas seu senso de direção e alguns índios ocasionais para guiá-lo. Embora ele carregasse um conjunto considerável de presentes para os nativos, seus suprimentos incluíam muito pouco alimento. Ele viveu fora do país por dois anos (The Nebraska Journal, 28/07/1940).

Figura 02 - Maria Cimino Lipkind e William Lipkind sentados, no lado esquerdo da foto na casa da artista Alice Yamin em Washington, EUA.

Foto de Aaron Siskind, sem data (provavelmente início da década de 1950).

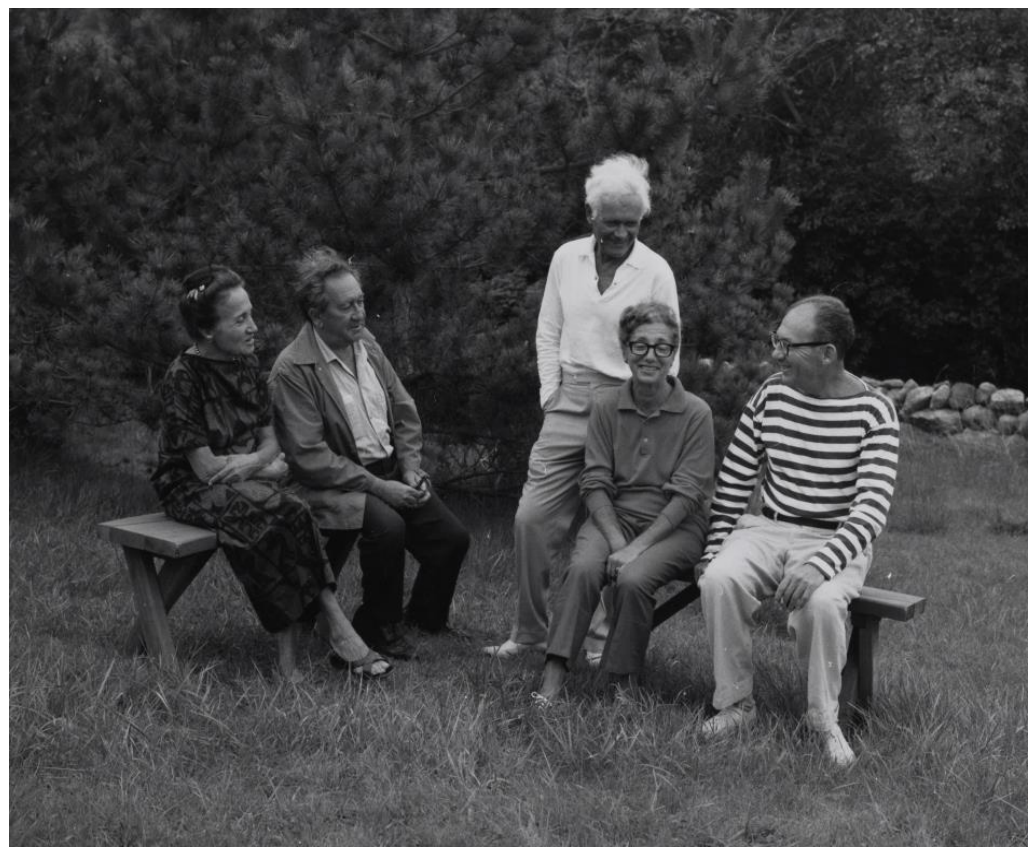

Fonte: Smithsonian Institution - Archives of America Art. 
Em carta enviada para Franz Boas, William Lipkind relata as condições de campo, as primeiras informações linguísticas, e assim como seu plano etnográfico. Ele esclarece que chegou a Fontoura há pouco mais de um mês:

Calor, solidão, uma imensa quantidade de mosquitos nocivos, todas as privações habituais da vida no sertão, temperar nosso prazer em encontrar o exótico e dominar a dificuldade. Se a falta de fundos adicionais ou a saúde não interromper meu estudo; estou decidido a ficar até ter aprendido os fundamentos da cultura Carajá. Eu gostaria de aprender algo sobre os seus vizinhos Tapirapé, Caiapó e Chavante. [...] Então eu espero fazer uma estadia prolongada com o Javaé, o braço interior dos Carajá, visitando suas cinco aldeias, e no meu regresso subir o Araguaia de Conceição à Leopoldina, visitando todas as vilas Carajá. (Lipkind 04/05/1938a).

Assim, pelas cartas do casal Lipkind, estima-se que eles fizeram sua base de campo entre os Karajá de Fontoura nos primeiros dias de abril de 1938.

Com William Lipkind e Buell Quain alojados entre os Gê no interior do Brasil como queriam a Columbia e o Museu Nacional, forma-se um triângulo de relações pessoais e profissionais entre Heloísa, Lipkind e Quain.

Buell Quain não vem acompanhado de sua esposa, que ficara nos Estados Unidos, e diferente de Lipkind, muda os planos iniciais e tenta pesquisar os Trumai, mas desiste por conta das dificuldades com o Serviço de Proteção aos Índios (SPI) (Wagley 1983) e pela ausência de suporte financeiro. Sendo assim, Buell Quain retoma o plano original de estudar os Gêe escolhe os Krahó nas proximidades da cidade de Carolina, Maranhão, no vale do rio Tocantins. Ele troca várias cartas com Heloísa, que é afetuosa.

Fazer coleções-tipos era uma meta etnográfica primordial e também política para satisfazer as pretensões do Museu Nacional e da Universidade de Columbia. O próprio Quain esclarece em carta de 27 de maio de 1939 para Heloísa Alberto Torres:

A senhora receberá um relatório sobre a cultura material [...]. A senhora ficará desapontada com a coleção. Ela tem interesse etnológico, mas...,sei que a senhora é antes de tudo uma cientista, mas imagino que seja politicamente importante para os museus atrair os olhos do público (Corrêa \& Mello, 2008:61).

Bell Quain provavelmente se referia à tipologia da cultura material krahô que, diferente dos Karajá ou dos Kaiapó, tem poucos artefatos plumários que atraiam mais os públicos dos museus. 
Heloísa constrói uma relação de afeição com Buell Quain, que a mantém a par de tudo o que acontece no campo, e confidenciando questões pessoais que envolviam, como por exemplo, o divórcio dos pais e suas brigas judiciais pelos bens do casal nos Estados Unidos. Já Heloísa Alberto Torres e William Lipkind eram cordiais, mas formais entre si. Lipkind agradece à Heloísa o apoio recebido, como o envio de material etnográfico para os Estados Unidos, e expressa o seu desejo de ensinar no Museu Nacional e ajudar a consolidar a Antropologia na instituição ao seu lado como linguista. Heloísa trocou cartas com ele quando estava em campo no Araguaia, dando-lhe suporte material e munindo-o de informações da família e sobre a iminência de uma Guerra Mundial.

Dois outros estudantes da Universidade de Columbia chegam ao Brasil. Ruth Landes (1908-1991) foi estudar o Candomblé em Salvador em $1938 .{ }^{6}$ O outro era Charles Wagley (1913-1991), ou Chuck, como era conhecido, que chegou em março de 1939 para realizar estudos etnográficos entre os Tapirapé, vizinhos Tupi dos Karajá (Wagley 1988:19).

Entre os Karajá, William Lipkind ganha o nome de "Guilherme". Ele apoia Charles Wagley na região do rio Araguaia, indicando os contados para apoio local de infraestrutura (Wagley 1983:12). Lipkind não só escreveu cartas para Charles Wagley preparando-o para o campo, como de fato deu-lhe suporte com barcos, aparelho de gravação de músicas e lhe fez companhia na visita à primeira aldeia dos Tapirapé. Ao mesmo tempo, Lipkind avançava na sua etnografia karajá, como explicou para Boas:

Eu tenho tido sucesso mais do que esperava até agora. Eu entendo a maior parte do que eu ouço e posso falar um pouco, apesar da dificuldade da língua. Maria e eu fomos adotados na parte baixa da aldeia de Fontoura, temos nomes Carajá e parentes novos. Exceto algumas cerimônias e atividades de estação chuvosa, eu tenho visto de tudo, desde o nascimento até o funeral. [...] Eu tenho encontrado coisas emocionantes: uma couvade bastante completo, compra e venda de espíritos inimigos, xamanismo e um complexo de feitiçaria de pesadelo, uma casa de homens e um complexo de iniciação [...] (Lipkind 06/05/1938b).

William Lipkind seguia orientação fiel do modus operandi da Antropologia Boasiana do "four fields", que desenhava um saber fazer antropológico espelhado em um tipo ideal de antropólogo enquanto provedor de capital cultural que, ao ser reconhecido pela produção acadêmica (tese, artigos, coleções, fotografias), abriria portas para alcançar posições sociais e profissionais para ensinar antropologia ou ser curador de grandes museus nos Estados Unidos e nas redes acadêmicas. 
Nas cartas trocadas e em seus diários de campo nota-se uma predileção pelo estudo da língua karajá. Ele registrou aspectos culturais e sociais participando de um processo, de acordo com ele, para se tornar xamã (hyry). Segue assim o princípio norteador do culturalismo que segundo o qual um costume deveria ser estudado em detalhes como parte de um todo cultural, e por meio do método indutivo se poderia fazer uso da comparação entre culturas, levando-se em conta a história local e os fatores ambientais (Bohanann \& Glazer 1973).

Tais dados foram apresentados em Carajá Cosmography, que foi publicado no The Journal of American Folklore em 1940, logo que voltou do Brasil. No artigo, Lipkind apresenta dados da cosmografia karajá que, embora sucinta, tem o mérito de ter sido a primeira tentativa de apresentar uma visão geral da ontologia nativa, trazendo dados inéditos para a época sobre o xamanismo. O tema parece ter sido a menina dos olhos do pesquisador. Ele escreve para Boas e narra que estava passando por um processo de iniciação xamânica. O assunto está presente na carta que Lipkind envia para a senhora Urbach (Lipkind 30/05/1939b), confidenciando que o pai médico queria que ele seguisse a mesma profissão, mas, na verdade, ele estava para ser diplomado com destaque, ou seja, se tornando um xamã, como frisa a matéria de O Globo de 1939 (5/11/1939).

O outro artigo de Lipkind a respeito dos Karajá foi publicado no ano de 1948 e integra o Handbook of South American Indians, editado por Julian Steward, que recebeu o título de The Carajá, no qual apresenta uma descrição genérica do grupo com aspectos da vida social e cultural.

William Lipkind foi um antropólogo formado em tempos de conflitos mundiais. O período entre as duas Grandes Guerras demonstra a ambiguidade do papel da antropologia. Se Franz Boas foi punido academicamente nos Estados Unidos por defender publicamente a não participação de antropólogos na Primeira Guerra Mundial (1914-1918), já na Segunda Guerra Mundial (1939-1945), antropólogos diretamente ligados a ele, como Ruth Benedict e William Lipkind, trabalharam no The Office of War Information (Price 2008). Ser antropólogo carregava igualmente ambiguidade de ser o cientista exótico que vivia perdido muito longe da civilização, como William Lipkind foi apresentado nos jornais no Brasil e nos Estados Unidos, e ao mesmo tempo ser um agente de mapeamento de culturas outras para facilitar estratégias de dominação e controle durante as guerras. A Antropologia é filha de uma era de violência, como expressou Almeida (2004:65).

Lipkind se move sobre uma superfície social (Bordieu 1996b:82) enrugada pelas contradições do processo epistemológico de produzir conhecimento antropológico, e modelada por uma geografia cultural e econômica 
que inseria tanto os Estados Unidos da América quanto o Brasil num cenário entre guerras mundiais. O tema da pesquisa de David Price foi a respeito da participação dos antropólogos estadunidenses como espiões de guerra e o envolvimento da Associação Americana de Antropologia (Price 2008).

No Brasil, as suspeitas de que havia informantes de guerra estavam presentes no meio intelectual. Por exemplo, Luís Castro Faria, em depoimento ao jornalista Bernardo Carvalho, testemunhou:

Falava-se que o William Lipkind tinha deixado o nome bastante comprometido, porque ele fazia relatórios políticos para os americanos. Isso é de ouvir falar, mas parece que num dos relatórios que escreveu sobre os Karajá havia uma menção a informações que ele deveria prestar ao Departamento de Estado. Parece que ele desempenhou e muitos americanos desempenharam uma função de observador (Carvalho 2006:07).

Além desse ambiente de suspeições nesse contexto de conflitos, pesava contra Lipkind o fato de ele ser judeu russo, e o ambiente antissemítico era evidente na época como já demonstrado.

O que se tem claro é que o antropólogo não teve capital político suficiente para construir uma relação acadêmica com o Museu Nacional via Heloísa Alberto Torres. A formação como linguista - como almejava o Museu Nacional - e a forte recomendação de Franz Boas e Ruth Benedict para Heloísa Alberto Torres não foram suficientes para convencê-la a contratá-lo. A tão esperada bolsa de estudos da Fundação Guggenheim foi concedida a Charles Wagley, que construiria uma longa e bem sucedida carreira no Brasil e nos EUA.

Mas se o capital político de Lipkind não logrou êxito no Brasil, o emprego temporário de professor na Universidade de Ohio e uma posição de antropólogo no governo dos Estados Unidos também não foram suficientes para sua consolidação na profissão de antropólogo. Ao voltar da Europa em 1947 para os Estados Unidos, depois de uma passagem pelo Hunter College de Nova York, ele se dedicaria à literatura infantil, atividade em que teria mais sucesso.

\subsection{A construção da coleção}

Em trabalho de campo durante o ano de 1938, Lipkind organiza uma coleção, grava músicas karajá em cilindros de cerâmica e produz um acervo fotográfico. A coleção e o material de campo seguem para o Museu Nacional aos cuidados de Heloísa Alberto Torres. 
Eu espero que você perdoe minha lista de encargos. Eu deixei sobre seus ombros. 1. Caixa com minha parte da coleção, o cilindro e algumas coisas pessoais. Eu mandei para o museu; despache aos cuidados da Profa. Ruth Benedict da Universidade de Columbia [...] 2. Envie-me uma impressão de todas as fotos e de maneira segura envie pelo correio aéreo os negativos para Maria Cimino Lipkind [...] Eu ficarei muito grato se você puder enviar a coleção e as fotos em breve. Gostaria de ouvir o American Museum antes de começar a coletar novamente (Lipkind 24/12/1938c).

Por sua vez, Charles Wagley organiza no Rio de Janeiro sua viagem ao Araguaia. A pedido de William Lipkind, ele envia um ofício, em 08 de março de 1939, ao Conselho de Fiscalização das Expedições Artísticas e Científicas no qual esclarece que Lipkind estava no Araguaia e parte da coleção que ele reunira já se encontrava no Museu Nacional para a triagem dos objetos que ficariam no Brasil e aqueles que deveriam seguir para a Universidade de Columbia (Wagley 1939).

Heloísa Alberto Torres despachou o documento em 19 de março de 1939, e anexou uma lista de objetos do que chamou de "Coleção do Museu" e outra lista de "Coleção Lipkind". Junto às duas listas há um certificado datilografado de exportação n. 17/39 do Conselho, em 18 de abril de 1939, emitido no nome de Heloísa Alberto Torres a favor de William Lipkind (Brasil 1939).

Aqui parece haver um ponto crucial para compreender a origem da coleção que hoje se encontra no Setor de Etnologia e Etnografia do Museu Nacional. A primeira remessa de artefatos coletados por Lipkind e referidos por ele no final de 1938 chega ao Museu Nacional para uma triagem sob os cuidados de Heloísa Alberto Torres. Ela seleciona o que deveria ir para Columbia e o que deveria ficar no Museu.

A "Coleção Lipkind", como foi nomeada por Heloísa, continha 154 objetos, e a coleção dos que ficaram no Museu tinha 132 objetos, tendo sido a primeira embarcada para os Estados Unidos. Encontrei nas correspondências entre William Lipkind e Ruth Benedict uma carta da empresa Draeger Shiping Co. INC., de 12 de junho de 1939, comunicando a chegada em Nova York de "2 cases of Indian jewelry" despachadas no navio Argentina (Vassar College Archives 1939). Lipkind recebe a confirmação da chegada da coleção nos Estados Unidos por meio de um telegrama de Heloísa Alberto Torres: 
Figura 03 - Telegrama de Heloísa Alberto Torres a William Lipkind

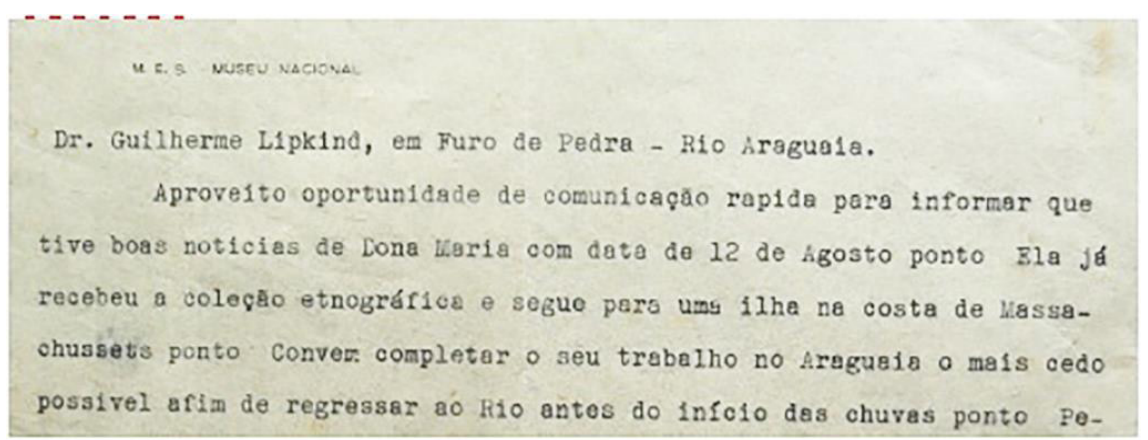

Desse modo, a data de 19 de março de 1939 oficializa$^{7}$ a "entrada" dos primeiros objetos da Coleção Karajá do Museu Nacional, que mudaria de nome: de "Coleção do Museu" para ser oficialmente denominada de "Coleção William Lipkind". No Museu Nacional, os artefatos começam a ser tombados a partir do número 28.611 de maneira sequencial.

Figura 04 - Braçadeira emplumada karajá.

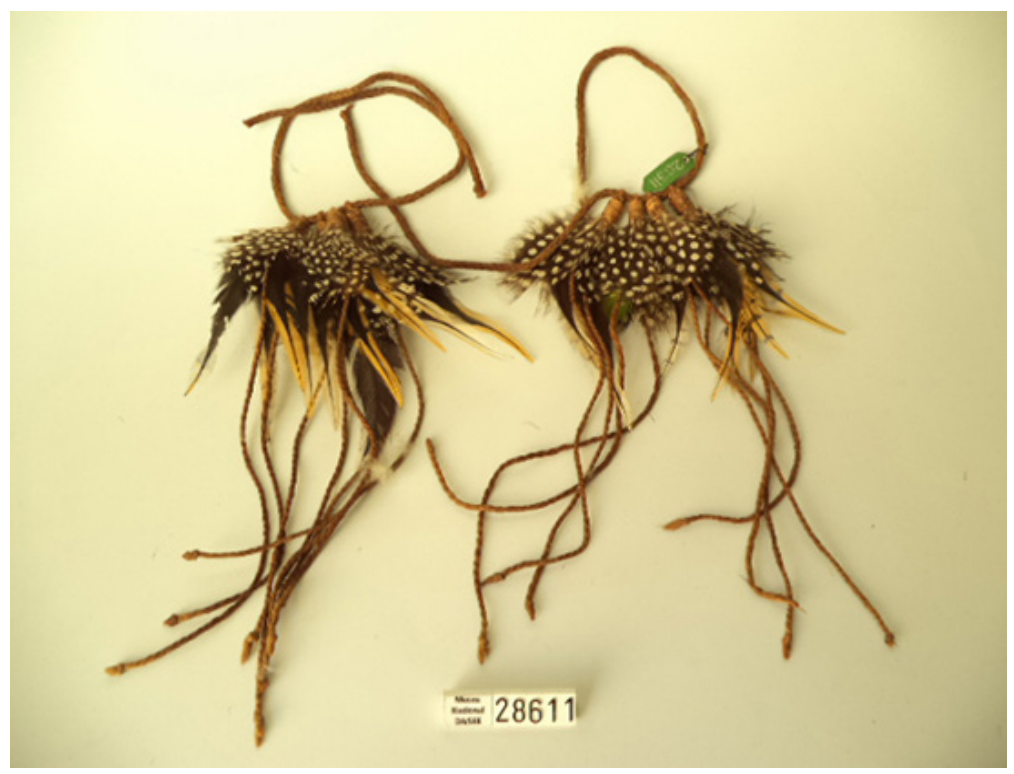

Coleção Lipkind. Primeiro número de tombo da Coleção Lipkind no Museu Nacional, $\mathrm{N}^{\circ}$ de registro: 28.611 (Ewbank 2015) 
Já no campo, Charles Wagley escreve para Heloísa Alberto Torres, em 01 de maio de 1939, a respeito de outra coleção que Lipkind estava fazendo, dessa vez com dados sobre os Javaé:

Lipkind acaba de voltar dos Javaé. Ele me disse que eles são um povo rico e produtivo e restam cerca de mil deles. Ele trouxe muitas coisas bonitas (cocares, etc.) e me pergunta se eu acho que você ficaria feliz com essas coisas maravilhosas para o Museu. Respondi por você; a coleção do Museu seria enriquecida com elas. A única coisa que me horrorizou ao fazer essas coleções Karajá é o preço que eles pedem. Vi Lipkind barganhando por coisas feitas para ele e eles queriam materiais que valiam quarenta e cinco mil réis para os cocares - suas razões para tais preços são boas - eles são sagrados, dizem eles. De qualquer modo, Lipkind está juntando uma linda coleção para você e eu espero fazer o mesmo nos Tapirapé (Corrêa \& Mello 2008:143).

Enquanto Wagley escrevia para Heloísa Alberto Torres, em 01 de maio de 1939, Lipkind, na mesma data escreve para Ruth Benedict sobre os fundos financeiros da pesquisa e sobre a coleção que estava fazendo, e esclarece:

Eu não sei como será para você levantar oitocentos dólares (...) [...] Talvez você possa obter um pouco disso na coleção que Dona Heloísa lhe enviou. Minhas coleções atuais devem ajudar mais. Tenho coisas muito melhores, chapéus de penas, máscaras, tembetá de cristal. Tenho dezesseis, em perfeito estado, [...] um colecionador da São Paulo me ofereceu um conto por tudo o que pude encontrar. [...] Eles são muito raros e bonitos. [...] pedra brilhante branca, quartzo, eu acho. Eu tenho tantos por pura sorte. Desenterrei um antigo cemitério e encontrei-os. Mesmo depois de Dona Heloísa fazer o seu pior, será deixado para fazer parte do dinheiro (Lipkind 01/05/1939a).

Os objetos javaé referidos por Charles Wagley como "coisas bonitas" são máscaras, tembetás de quartzo e materiais provenientes de um cemitério que Lipkind escavou numa antiga aldeia de Fontoura, na ilha do Bananal, e relatados de maneira entusiástica para Ruth Benedict. Eles foram incorporados à "Coleção William Lipkind", que já havia ganhado uma entrada no livro de tombo do Museu Nacional. Quando Lipkind termina a etapa de campo no final de 1939, avisa a Heloísa que: "I'am bringing a Carajá companion with me to Rio. The dance-masks had to be taken apart to be packed, and he'll assemble them in the museum. If you can arrange our passage on the Lloyd Brasileiro or Costeira, it would be helpful (Lipkind 02/09/1939c). 
Como esse material, inclusive as máscaras, chegam mais tarde, sua numeração de tombo no Museu Nacional começa com o número 30.684 e vai até 30.921. Finalmente, a última entrada da "Coleção William Lipkind" recomeça com o número 36.541 e termina com o número 36.653. Apesar de as peças serem em sua maioria karajá, a coleção é composta também por artefatos kaiapó e tapirapé.

\section{Tabela 01}

Coleção William Lipkind do Museu Nacional (UFRJ)

Entrada no livro de Tombo

\begin{tabular}{|c|c|}
\hline Objetos karajá & 437 \\
\hline Objetos kaiapó & 86 \\
\hline Objetos tapirapé & 01 \\
\hline Objeto Não Identificado & 03 \\
\hline TOTAL & $\mathbf{5 2 7}$ \\
\hline
\end{tabular}

\section{Tabela 02}

Coleção William Lipkind do Museu Nacional (UFRJ)

Localizados no Setor de Etnologia e Etnografia

\begin{tabular}{|c|c|}
\hline Objetos karajá & 371 \\
\hline Objetos kaiapó & 82 \\
\hline Objetos tapirapé & 0 \\
\hline Objeto Não Identificado & 01 \\
\hline TOTAL & $\mathbf{4 5 4}$ \\
\hline
\end{tabular}

\section{Tabela 03}

Coleção William Lipkind do Museu Nacional (UFRJ)

Subgrupos Karajá - Entrada no livro de Tombo

\begin{tabular}{|c|c|}
\hline Objetos karajá & 303 \\
\hline Objetos javaé & 134 \\
\hline TOTAL & $\mathbf{4 3 7}$ \\
\hline
\end{tabular}

\section{Tabela 04}

Coleção William Lipkind do Museu Nacional (UFRJ)

Subgrupos Karajá - Localizados no Setor de Etnologia e Etnografia

\begin{tabular}{|c|c|}
\hline Objetos karajá & 264 \\
\hline Objetos javaé & 107 \\
\hline TOTAL & $\mathbf{3 7 1}$ \\
\hline
\end{tabular}


Figura 05 - Cerâmica karajá utilitária e/ou cerimonial para armazenagem e serviço. №. de registro: 30.705

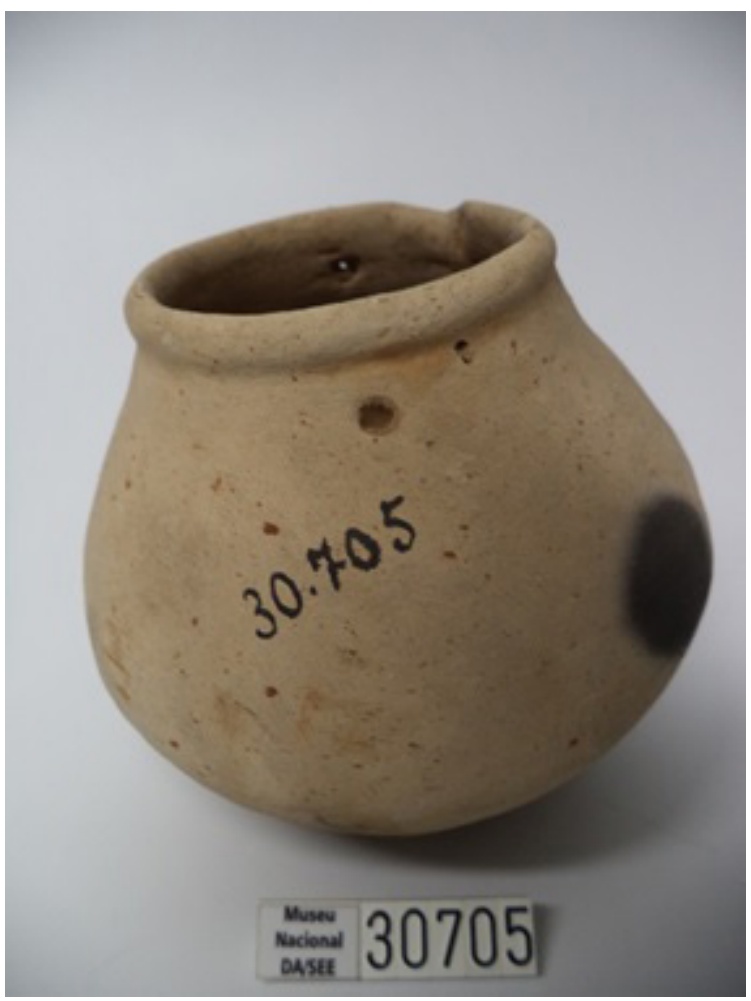

(Ewbank 2015)

Figura 06 - Tembetá de quartzo.

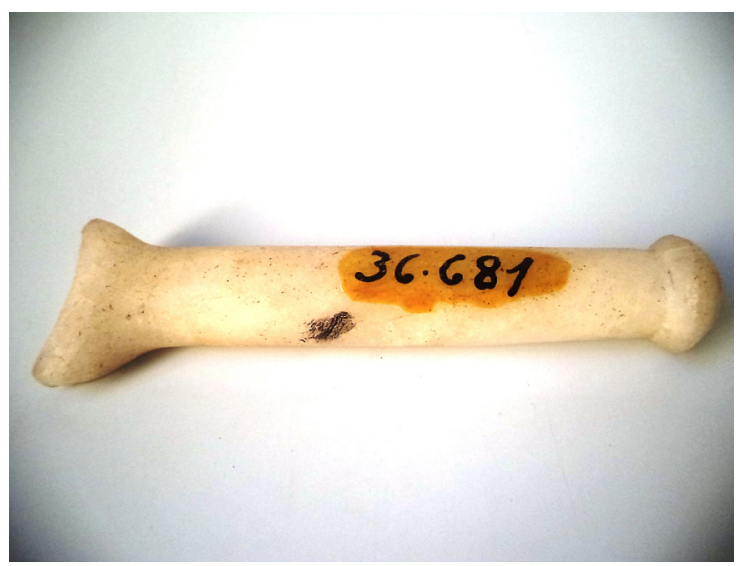

Coleção William Lipkind. Nº. de registro: 36.681 (Ewbank 2015) 
Figura 07 - Bonecas karajá.
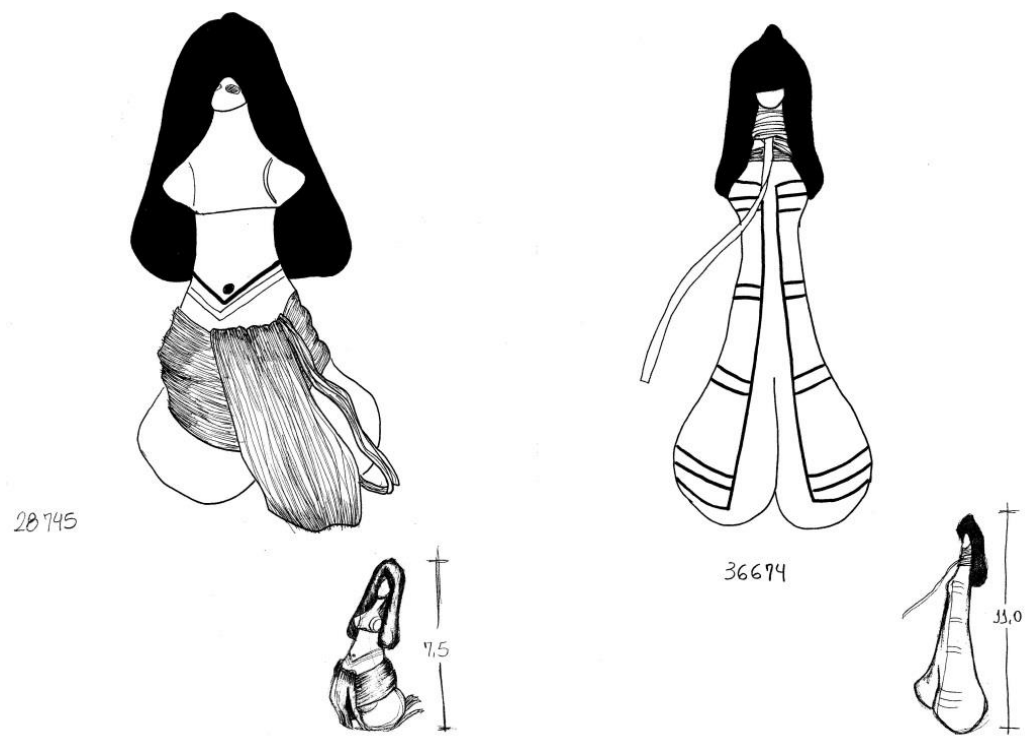

Coleção William Lipkind. $\mathrm{N}^{\circ}$. de registro: 28.745; $\mathrm{N}^{\circ}$. de registro: $36.674 \mathrm{e}$ desenho de Carol Juliano R. da Costa (2016)

A prática de colecionar moveu Lipkind para alcançar dois propósitos. O primeiro foi fazer do colecionismo um meio de aprimorar as relações acadêmicas com a direção do Museu Nacional, ou seja, construir um capital simbólico junto a Heloísa Alberto Torres, que acabou por não ter êxito.

De qualquer forma, como testemunhou a própria Heloísa Alberto Torres, Lipkind fez uma expressiva coleção do ponto de vista etnográfico, que ela chama de "bela" para os propósitos museais da época e que ficou tombada sob a guarda no Museu Nacional.

Dos 454 artefatos localizados na Seção de Etnologia e Etnografia da instituição, foi possível produzir uma relação étnico-quantitativa e tipológica da coleção que adapto a seguir de Ewbank e Grippo (2016), sendo que as definições tipológicas seguem a normatização definidas por Berta Ribeiro (1988). 


\section{Tabela 05}

Classificação tipológica e por etnia da Coleção William Lipkind

\begin{tabular}{|c|c|c|c|c|c|c|c|c|c|}
\hline $\int^{\text {Tipologia }}$ & 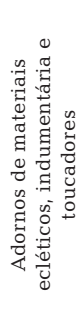 & 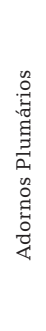 & 疍 & 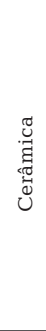 & $\begin{array}{l}0 \\
0 \\
0 \\
0 \\
0 \\
0 \\
0 \\
0 \\
0 \\
0 \\
0 \\
0\end{array}$ & 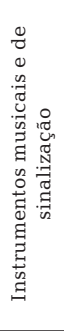 & 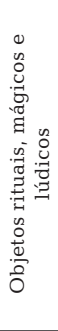 & 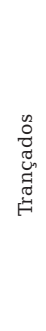 & 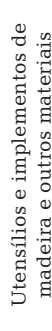 \\
\hline Karajá & 28 & 37 & 21 & 54 & 17 & 4 & 36 & 28 & 39 \\
\hline Javaé & 9 & 17 & 7 & 0 & 32 & 9 & 29 & 0 & 4 \\
\hline Kayapó & 71 & 4 & 2 & 0 & 0 & 0 & 1 & 4 & 0 \\
\hline $\begin{array}{c}\text { Sem } \\
\text { Procedência }\end{array}$ & 0 & 0 & 1 & 0 & 0 & 0 & 0 & 0 & 0 \\
\hline Total & 108 & 58 & 31 & 54 & 49 & 13 & 66 & 32 & 43 \\
\hline
\end{tabular}

Nota-se que há uma predominância de artefatos plumários/indumentária/toucadores e de objetos rituais/mágicos, refletindo o interesse do pesquisador em obter objetos vistosos do ponto de vista de uma exposição museológica e o seu interesse etnográfico pelo xamanismo.

O segundo propósito de Lipkind, impulsionado pela prática da época, foi o de fazer coleções como meio de ganhos financeiros. E aqui o pesquisador não ponderou atitudes escrupulosas e atuou através de uma prática etnográfica construída a partir de uma perspectiva conceitual do Ocidente que, justificada por fazer ciência, produzia hierarquia de saberes, a violência simbólica e o exercício do poder, trazendo as marcas de antropologia enquanto empresa imperial colonial, como nos lembram Edward Said (2007) e Jonhanes Fabian (2014).

Em sua busca por coleções, Lipkind adentrou em duas áreas sensíveis aos Karajá. Escavou um cemitério e removeu da aldeia várias máscaras de Aruanã ou ijasò, que estão relacionadas a um complexo ciclo ritual que inclui a iniciação masculina e práticas culturais ligadas aos mortos, gênero, corpo, recursos alimentares e produção de objetos materiais. As máscaras ficam confinadas na Casa de Aruanã, conhecida como Casa dos Homens (Lima Filho1994; Toral 1992; Petesch1993, 1996; Rodrigues1993).

As máscaras, quando não vestidas por homens dançando contra as mulheres no pátio ritual, não podem ser vistas por mulheres ou crianças. $\mathrm{O}$ mito diz que, se as mulheres têm acesso a essas máscaras, elas podem ser abusadas sexualmente e jogadas no rio Araguaia. Lipkind escreveu sobre um incidente em que os homens abusaram sexualmente de uma mulher porque ela teve acesso ao restrito mundo sagrado. Talvez ela tivesse entrado na Casa de Aruanã. 


\subsection{Tornando-se xamã e o retorno aos Estados Unidos}

William Lipkind, após sete meses de campo, viaja ao Rio de Janeiro para embarcar sua esposa para Nova York.

Com a chegada da estação das chuvas, com a esposa nos Estados Unidos e vendo sua chance como linguista no Museu Nacional, financiado pela Sociedade Brasil-Estados Unidos, ser reduzida pela não aprovação de seu nome por Heloísa Alberto Torres, William Lipkind retorna ao campo para cumprir seu plano de trabalho. Muda a sua base de campo para o pequeno povoado Furo de Pedra ${ }^{8}$, mais próximo das aldeias dos Tapirapé e faz o reconhecimento de várias aldeias cobrindo os três subgrupos, Karajá, Javaé e Xambioá.

À medida que a pesquisa de campo avançava, a relação de Heloísa Alberto Torres com Lipkind, já no ano de 1939, se torna quase hostil, como registrado na seguinte carta que ela escreveu a Bell Quain:

Fui informada de que os planos da Senhora Pieri de conseguir professores americanos através da Sociedade Brasil-Estados Unidos falharam inteiramente. Essa era a oportunidade que o Dr. Lipkind esperava para poder vir para o Brasil.

A Dra. Benedict escreveu para Ruth [Landes] dizendo que ela achava que o Dr. Lipkind e outros dois (Lasser e Kennard, acho) seriam bons para oferecem cursos de linguística aqui. Não tenho o menor compromisso com o Dr. Lipkind [...] (Heloísa Alberto Torres para Buell Quain em 17/05/1939 apud Corrêa \& Mello 2008:58, grifos meus).

A única mulher do primeiro grupo de estudantes da Universidade de Columbia, Ruth Landes, escreveu a Ruth Benedict demonstrando indignação pelo fato de Heloísa não querer Lipkind trabalhando no Museu Nacional, pois alegava que havia um crescente sentimento antissemítico no Brasil e ela tinha suficientes problemas no Museu Nacional (Corrêa \& Mello 2008:31).

O distanciamento de Heloísa Alberto Torres em relação a William Lipkind é confidenciado por ele à sua orientadora Ruth Benedict:

Recebi uma carta da Sra. Pierre, que foi afastada da política brasileira pelo rumor de que ela é uma espiã nazista. Ela me disse que Dona Heloísa Torres saiu para Nova York em junho e vai fazer arranjos para a escola de etnologia no Rio. Ela quer alguém "chamado Wagley Quain como professor porque é mais jovem e mais fácil de administrar do que você". Quain me escreveu que Dona Heloísa lhe ofereceu o emprego e ele recusou, insistindo que ela devolva a mim, não sei o que ela tem contra mim. Nós nos separamos como melhores amigos (Lipkind 01/05/1939c). 
Sua intenção era voltar de Conceição do Araguaia (PA) para Leopoldina (GO), e de Anápolis partir de trem para a cidade do Rio de Janeiro.

Porém, William Lipkind muda de roteiro em sua volta. Em vez de escolher Leopoldina, segue para Belém, chegando em 15 de novembro de 1939 acompanhado de um javaé (subgrupo Karajá), quando concedeu uma entrevista para o jornal O Globo.

Figura 08 - Matéria de O Globo de 15/11/1939.

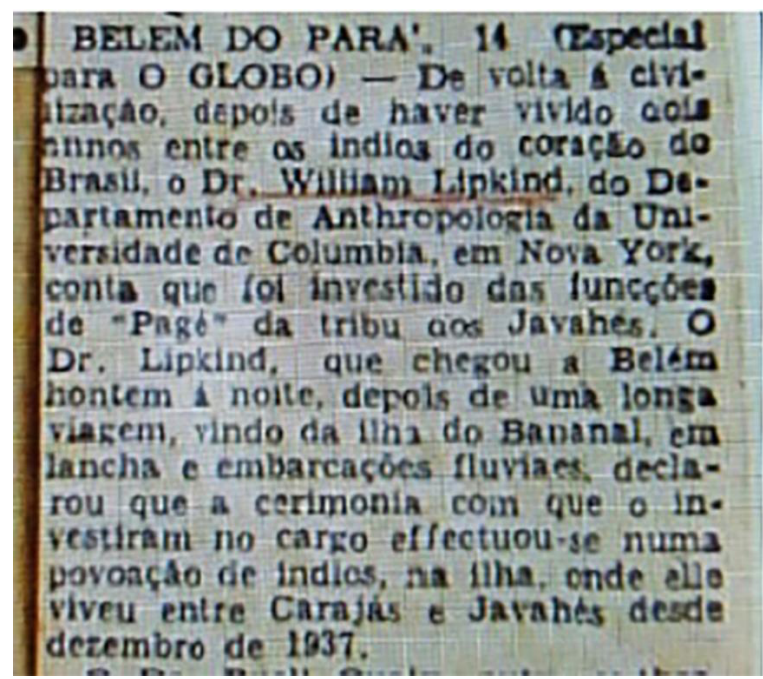

Fonte: Acervo O Globo

Uma vez na cidade do Rio de Janeiro, William Lipkind embarcou no navio Uruguay em 31 de dezembro de 1939 para Nova York (Ancestry 2014m). Não voltaria mais ao Brasil.

\subsection{A Etnografia na Guerra, a Universidade de Ohio e a Literatura Infantil}

William Lipkind volta para New York e não consegue trabalho fixo. Ao consultar o censo de 1940 dos Estados Unidos, encontrei informações de que ele não ensinava em universidades, morava numa casa alugada e tinha salário proveniente de atividades particulares (Ancestry 2014n).

Charles Wagley comenta em carta escrita para Heloísa Alberto Torres em 20 de fevereiro de 1940 ter recebido várias cartas de Columbia, "mas nenhuma notícia de Lipkind. Temo que ele tenha se ofendido com alguma coisa, mas isso não me incomoda" (Corrêa \& Mello 2008:174).

No mês de junho de 1940, Heloísa Alberto Torres recebe uma correspondência de Charles Wagley de Nova York dizendo que havia encontrado 
Lipkind e que ele havia dito que teria mandado o relatório quando passou pela ilha de Trinidad em sua viagem de volta aos Estados Unidos, mas Wagley duvidou (Corrêa \& Mello 2008: 186).

Em relação ao tema da coleção dos Karajá e sobre Lipkind, Charles Wagley ainda escreve três cartas para Heloísa Alberto Torres. A primeira foi em 05 de outubro de 1940, quando ele diz: "Continuo a perguntar a Lipkind por seu relatório (grifo na carta) sem sucesso" (Corrêa \& Mello, 2008: 200).

Em 20 de novembro de 1940 ele escreveu que havia se encontrado com Lipkind. Descreveu que ele estava muito preocupado à procura de emprego e que havia feito um projeto para a Fundação Guggenheim pedindo verba para ele voltar ao Brasil [...] (Corrêa \& Mello, 2008: 203).

Heloísa Alberto Torres, em carta para Charles Wagley, em 12 de janeiro de 1941, enfatizou que escreveu para Franz Boas sobre o pedido de bolsa solicitado por este para Lipkind voltar ao Brasil:

Recebi uma carta de Boas me comunicando que tinha solicitado uma bolsa para o Lipkind vir para o Brasil para continuar as suas pesquisas e fazer o trabalho de ensino de Antropologia no Museu Nacional e que ele (Boas) desejava que eu escrevesse ao sr. Aydellote da Gugenheim a respeito. Eu fiz a vontade dele e escrevi apenas que (ilegível) não tinha nenhuma objeção a que ele voltasse para o Brasil para continuar suas pesquisas, embora ele não pudesse recomeçá-las enquanto não satisfizesse os requisitos legais de fornecimento do relatório, mas que eu me opunha a que ele viesse cooperar com o Museu Nacional. [...] Comuniquei também ao Boas que a coleção do Lipkind que está aqui no Rio, e que eu disse a ele que faria exportar quando tivesse recebido o relatório, está correndo o risco de ser confiscada (Corrêa \& Mello, 2008:208, grifo meu).

De fato, Heloísa Alberto Torres tinha assumido uma posição dura contra Lipkind na correspondência que enviou para a Fundação Guggenheim em 02 de janeiro de 1941.

O Dr. Lipkind mostrou-se inteiramente desrespeitoso em relação às várias demandas que lhe fiz ao Museu Nacional, e que tinha a ver com a apresentação de relatórios sobre suas atividades no Brasil - creio, assim, que ele não deseja trabalhar em cooperação com o Museu Nacional. Penso também que o Dr. Lipkind não é a pessoa adequada para lidar com nossos estudantes. Embora ele seja inteligente e hábil, os brasileiros têm uma inclinação para a crítica, e estou certa de que a atitude de superioridade do Dr. Lipkind não teria a simpatia de nossos estudantes. Creio que seria muito mais proveitoso para eles se fosse possível enviar um linguista competente com um temperamento mais adequado" (Corrêa \& Mello, 2008: 211). 
Na mesma data da carta acima, Heloísa Alberto Torres escreveu para Franz Boas alegando que ajudou Lipkind até financeiramente e que ele não havia mandado os relatórios. Argumentou que Charles Wagley e Buell Quain mandaram os relatórios, mas Lipkind, assim como Ruth Landes, não enviou os relatórios para o Museu Nacional e que esperava "que ele tivesse uma atitude diferente em relação aos outros assuntos", e finaliza: "Lamento dizer que a sua coleção privada poderá ser confiscada por falta de requisitos legais [...] Adiei esta decisão até agora, mas não creio poder adiar mais essa situação" (Corrêa 2008 \& Mello: 212 e 213, grifo original).

Finalmente, no dia 26 de março de 1941, Charles Wagley retoma o tema de William Lipkind e da coleção quando escreve para Heloísa Alberto Torres:

Também tive uma discussão com Lipkind hoje. Pobre rapaz, também ele não consegue aprender a respeito das pessoas e veio me pedir para acertar as coisas para ele com você. Ele quer tanto voltar ao Brasil e não consegue entender por que não pode. Ele acha que estou tentando guardar tudo para mim. Ficamos um pouco esquentados - mas não é minha função, na minha atual situação, dizer-lhe "verdades", por isso tentei ser gentil. Ele não é mau - mas infeliz (Corrêa \& Mello 2008: 227, 22).

Tendo em vista esse desfecho desolador para a carreira de antropólogo de William Lipkind no Brasil, ele se muda para Ohio e consegue uma posição temporária de professor de Antropologia na universidade. Ministra cursos de Introdução de Sociologia e de Antropologia e um Seminário de Antropologia para pós-graduação e incentiva alunos para um pequeno projeto de pesquisa de antropologia na biblioteca. Busca alunos para curso de linguística e reclama para Franz Boas das dificuldades de obter livros na biblioteca (Lipkind 7/02/1942a).

Franz Boas alerta Lipkind que, se ele não fizesse um novo apontamento para professor na Universidade de Ohio, seria o fim da carreira dele como antropólogo. Franz Boas ficara sabendo da possível desistência de Lipkind por meio de Ruth Benedict. William Lipkind agradeceu e permaneceu em Ohio (Boas 25/05/1942; Lipkind 29/05/1942b).

William Lipkind escreveu para Ruth Benedict informando que havia recebido um convite para trabalhar no Brasil na"Rubber Reserve Company" como técnico de campo e, como a situação dele na Universidade de Ohio era instável, estava propenso a aceitar a oferta ou outro emprego na Guerra. Porém, Lipkind desistiu da posição no Brasil e, segundo as informações do National Anthropological Archives, ele permaneceu dois anos na Universidade Estatual de Ohio. Após esse período, ele participou do Army Specialized Training Program, Curriculum 705, Foreign Area and Language 
Studies, habilitando para se integrar ao Office of War Information com atuação na Inglaterra e na Alemanha, e retornando ao seu país em 1947 (Lipkind 05/02/1943).

Uma vez nos Estados Unidos, William Lipkind ensinou Antropologia na Universidade de Nova York e literatura infantil no Hunter College, mas direcionou seu foco para a Literatura, sua área de estudo no mestrado, e se tornou conhecido autor de literatura infantil, assinando apenas Will. Em parceria com o ilustrador Nicholas Mordvinoff, Lipkind formou a dupla Will e Nicolas. Publicaram vários livros. Com o livro Finders Keepers foram premiados com a Caldecott Medal of the American Library Association em 1951.

Dessa maneira, a intenção de William Lipkind de escrever novelas, expressa nas entrevistas de Belém em 1939 e em Nebraska em 1940, realizou-se de alguma forma, pois alguns dos temas de seus livros infantis reportam à sua experiência etnográfica no interior do Brasil Central. E a Coleção Karajá feita por ele permaneceu no Museu Nacional sem o catálogo tão esperado por Heloísa Alberto Torres, o que lhe custou a não permanência como pesquisador no Brasil.

Em 03 de outubro de 1974, o New York Times publica que William Lipkind havia falecido no dia anterior em sua casa, com 69 anos de idade, deixando viúva Maria Cimino e o irmão Norman.

\section{A vida das coisas da coleção Lipkind...}

A pesquisa realizada sobre a biografia de William Lipkind e a feitura de uma coleção, em sua maioria de artefatos do grupo Karajá, me permitem entrelaçar alguns domínios conceituais e empíricos.

Considerei oportuno mapear a trajetória do antropólogo estadunidense e as alocações e os deslocamentos no espaço social onde ele se moveu, possibilitando demarcar os capitais políticos, simbólicos e sociais presentes na trama de se fazer antropologia no Brasil - no caso, no Museu Nacional e nos Estados Unidos na Universidade de Columbia (Bourdieu 1996b: 81). Nessa trajetória conectada com uma rede de atores e instituições, destaco algumas interseções que me parecem importantes: a prática de se fazer antropologia no contexto de Guerra Mundial; a feitura de coleções inserida na orientação epistemológica do culturalismo, enquanto moeda de troca científica, mas também ação movida por cobiça financeira, tendo os museus dos Estados Unidos como receptores das coleções e, finalmente, a constante necessidade da desnaturalização das práticas do colecionamento e de recursos expositivos que se movem ainda entre o exótico e as experiências compartilhadas com grupos representados nas reservas dos museus, como é o caso dos Karajá. 
Apesar de diversos estudos antropológicos insistirem na importância de a antropologia rever criticamente concepções e práticas herdadas da maneira de pensar e de se relacionar com a "alteridade", não é raro nos depararmos com situações vinculadas ao ofício do antropólogo diretamente ligado às instituições museais, de maneira especial àquelas que possuem acervos etnológicos, permanecendo num círculo vicioso que vai do espetáculo ou do exotismo dos "objetos" à rotinização do esquecimento a respeito das trajetórias de tais objetos, desde as condições em que são adquiridos até serem depositados nas "reservas técnicas" e expostos nos circuitos museais. Em função da dificuldade de romper com essa rotinização que propicia um estado de inércia acrítico, ignora-se a prática das assimetrias incrustadas em nossos olhares e práticas. Desnaturalizar tais assimetrias sobre o 'Outro' dentro do museu é exercício necessário, participando-se das principais pautas das reflexões críticas sobre as práticas colecionistas e museais (Pereira \& Lima Filho 2016).

Esta reflexão faz sentido já nas primeiras experiências de contato dos Karajá com a Coleção Lipkind através de um líder karajá que esteve presente durante a abertura da exposição de artefatos plumários no Museu Nacional, no Rio de Janeiro, em 2012. Sem saber que algumas máscaras estavam na coleção, o homem, acompanhado por duas mulheres, ficou surpreso e preocupado. Ele explicou que as mulheres não podiam ver as máscaras e que no passado, as máscaras de alguns Aruanãs foram retiradas de sua aldeia, o que causou muita consternação entre os Karajá e, de modo especial, entre os xamãs. Ele insistiu em voz baixa que as mulheres não podiam ver as máscaras e, assim, foi iniciado um processo de interlocução com o Museu Nacional a fim de se retirarem as máscaras da exposição.

Algum tempo depois, outro homem karajá, que era um adolescente na época da minha pesquisa de campo em 1989, contou-me, por e-mail, que ele ia entrar com uma ação contra o Museu Nacional, porque viu no site o folder da Mostra Plumária Karajá que continha uma foto de uma das máscaras Aruanã. Ele me advertiu que na internet as mulheres tinham acesso livre e que a máscara fora exposta. Eu disse então que o fato aconteceu pela falta de conhecimento por parte do Museu Nacional desse aspecto restritivo da cultura karajá e estava garantida a retirada do folder e das máscaras da exposição, o que de fato aconteceu.

Assunto como este foi objeto de reflexão de Rafael de Andrade que, estudando a relação entre as coisas e o xamanismo karajá, relata que em 2015 foi realizada uma reunião dos xamãs karajá para discutir assuntos relevantes, como os casos dos suicídios entre os jovens. Nessa mesma reunião, assessorados por um procurador da República, discutiu-se sobre quais providências deveriam ser tomadas com as máscaras de Aruanã em posse dos brancos (Andrade 2016: 92). 
De qualquer forma, fosse qual fosse o meio de convencimento de Lipkind para transportar máscaras de Aruanã - sendo que Ehrenreich fez o mesmo saindo às escondidas pela praia, ele teve a conivência de algum karajá, seja para a retirada das máscaras da Casa de Aruanã, seja para vir ao Rio de Janeiro a fim de ajudar a montá-la, como noticiou em carta para Heloísa Alberto Torres. Este fato, que diz respeito ao segredo das máscaras e ao jogo de poder entre os gêneros karajá, provocou uma reação imediata do jovem líder que viu as máscaras expostas no Museu Nacional como exemplo da plumária do grupo. Um outro interlocutor karajá esclareceu, em diferente momento da pesquisa, que a conivência de algum xamã no ato de profanação da Casa de Aruanã tem um efeito maléfico contra o xamã que burlou as regras por parte das entidades espirituais associadas às mascaras. Assim, o presente (a exposição de componentes da coleção) evoca o passado (a retirada das máscaras em 1939 e outros tempos), reatualizando, ou como quer Sahlins, organizando as estruturas de significação da História (Salhins 2004).

Esses acontecimentos etnográficos podem ser correlacionados com a reflexão de Priscila Faulhaber (2005), que registrou os depoimentos de anciãos e especialistas tikuna sobre objetos coletados por Curt Nimuendaju, esclarecendo que os artefatos são concebidos como objetos vivos, mediadores entre níveis cosmológicos. E a reflexão de João Pacheco de Oliveira segue na mesma direção ao compartilhar sua experiência analítica a respeito de um objeto da reserva técnica do Museu Nacional e os Bororo:

As coleções etnográficas, uma vez retiradas das aldeias e dos seus contextos de utilização cotidiana e ritual, tendem a ser transformadas em abstrações sociológicas, nas quais a história e a reflexividade estão congeladas. A análise de uma pintura de um menino bororo, localizada no Museu Nacional, permite reencontrar estórias esquecidas e encobertas, apresentando uma abordagem alternativa que propõe uma historicização radical e discute o jogo de forças que estão em torno da aquisição, classificação e exibição de objetos etnográficos (Oliveira 2007:73).

A coleção, como a feita por William Lipkind há mais de 70 anos, aparentemente desprovida de sentido político, justificada por um ato de fazer antropológico do passado ou cobiça mercadológica, tem no tempo atual necessariamente uma dimensão política que elimina qualquer ingenuidade da Antropologia, dos Karajá assim como do antropólogo. 
Para um grupo indígena como os Karajá, que possui uma longa história de contato interétnico, que aprendeu a sobreviver e a lutar por seu território, por acesso à saúde e à educação intercultural, o reencontro com uma coleção de objetos do passado, como a Coleção William Lipkind, ganha uma dimensão de agência política importante. O caso das máscaras expostas tanto na exposição quanto no convite disponibilizado no site do Museu Nacional encontra ressonância na reflexão de João Pacheco de Oliveira.

O que mais importa hoje para os indígenas é a questão do controle sobre os múltiplos usos que podem vir a ser feitos com os dados da pesquisa, bem como saber em que medida análises e interpretações avançadas podem afetar o seu modo de vida, seus direitos e as representações sobre si mesmos (Oliveira 2013: 60).

Desta forma, se o estudo sobre a trajetória de William Lipkind e a coleção que ele formou me permitiu compreender, atento ao "presentismo e ao historicismo", como sugeriu Stocking Jr. (1982), os meandros e os jogos representativos de ciência e de poder envolvidos no modo de fazer Antropologia em tempos formativos nos Estados Unidos e no Brasil, as primeiras experiências de visibilidades desta coleção já demonstram que os Karajá de fato querem, podem e devem intervir nos usos e nos abusos de seus objetos culturais num convite para desnaturalizar assimetrias. Outras trilhas chegarão até a Coleção William Lipkind do Museu Nacional.

Recebido em 10 de março de 2017

Aprovado em 03 de outubro de 2017

Manuel Ferreira Lima Filho é Professor da Faculdade de Ciências Sociais da Universidade Federal de Goiás, Goiânia/GO, Brasil.

E-mail: <manuellimafilho@gmail.com>

\section{Notas}

* Pesquisa financiada com recursos do CNPq, Comissão Fulbright-CAPES e Faperj. 
1 Sabe-se da existência de objetos karajá nos seguintes museus: Museu da Basileia (Suíça), O Museu Nacional de História Natural de Washington e de Nova York (EUA), Museu do Índio (EUA), Museu du quai Branly, que recebeu as coleções do então Museu do Homem (França) e Museu de Etnologia de Viena. No Brasil são conhecidas as coleções do Museu de Arqueologia e Etnologia (USP), Museu Antropológico (UFG), Centro Cultural Jesco Putkammer (PUC-GO), Museu Zoroastro Artiaga (Goiânia), Museu Paraense Emilio Goeldi (MCT), Museu do Índio (RJ) e ainda o acervo da Secretaria Municipal de Cultura de São Paulo. No caso particular do Museu Nacional (RJ), são conhecidas as coleções de Castro Faria (década de 1950) e a de Maria Heloísa Fénelon Costa (final da década de 1950).

2 O modo de fazer as bonecas karajá recebeu dois registros no Iphan. Ritxòkò: Expressão Artística e Cosmológica do Povo Karajá foi registrado na categoria Formas de Expressão; Saberes e Práticas Associados ao modo de fazer Bonecas Karajá foi registrado na categoria Saberes, ambos em 25 de janeiro de 2012.

3 A pesquisa se concentrou nos arquivos do Museu Nacional (UFRJ), MAST (Rio de Janeiro), Casa de Cultura de Itaboraí (RJ), acervo do New York Times (EUA), National Archives - National Museum of Natural History (Smithsonian Institution), Newspaper.com, Columbia University Archives, Hunter College Archive, College of City of New York Library Archives. United States Federal Census [database on-line no site ancestry.com; American Philosophical Society; Archives and Special Collections - Vassar College]. A pesquisa teve como central de apoio a Olin Library e Archives of Washington University of Saint Louis.

4 Embora apareçam os nomes de Bekie e Buelle nos censos, o nome Bessie se sobrepõe aos demais.

5 A respeito do início da Antropologia nos Estados Unidos, as ideias de Franz Boas e suas repercussões na Universidade de Chicago foram analisadas por Stocking Jr. (2004).

6 Ruth Landes escreveria o livro City of Women (1947) e teria uma carreira bem sucedida na Antropologia. Ver Landes, S. Ruth. The City of Women. Introduction by Sally Cole. New York: Macmillan. Ver ainda (Wang, 2010).

7 Aqui cabe uma observação. Charles Wagley afirma que deixou o Rio de Janeiro em fevereiro de 1939 na direção de São Paulo (Wagley 1983: 07). Ele escreve a primeira carta para Heloísa Alberto Torres em 18 de março de 1939 (Corrêa \& Mello 2008: 131) e o ofício ao Conselho a respeito de parte da Coleção Karajá que se encontrava no Museu Nacional para triagem e emissão da guia de exportação tem a data de 08 de março de 1939, na cidade do Rio de Janeiro. Provavelmente, ele deixou o ofício assinado traduzido por Heloísa Alberto Torres, que despachou à mão em 19 de março de 1939 como membro do Conselho.

8 Furo de Pedra era um antigo povoado do Médio Araguaia ocupado por camponeses em 1910, e que servia como entreposto dos barqueiros que traziam sal, óleo, tecidos e levavam em troca couro de animais. Devido às constantes inundações do rio, a população mudou-se para um morro na mesma margem do rio que, em 1931, foi o local escolhido pelos Dominicanos de Conceição do Araguaia para instalar um posto missionário, hoje a cidade de Santa Terezinha (Esterci1987). 


\section{Referências bibliográficas}

ALMEIDA, Mauro W. B. de. 2004. "A etnografia em tempos de guerra: contextos temporais e nacionais do objeto da antropologia". In: Fernanda Arêas Peixoto, Heloísa Pontes \& Lilia Moritz Schwarcz (orgs.), Antropologia, histórias, experiências. Belo Horizonte: Editora da UFMG. Pag. 61-82.

ANDRADE, Rafael S. de. 2016. Os huumari, o obi e o hyri: a circulação dos entes no cosmo Karajá. Dissertação de Mestrado. Universidade Federal de Goiás.

ANCESTRY. 2014a. U.S. Social Security Death Index, 1935-2014 [database on-line]. Provo UT, USA: Ancestry. com Operations Inc., 2011. Original data: Social Security Administration. Social Security Death Index, Master File. Social Security Administration. Disponível em: http://search.ancestry. com. Acesso em 09/11/2014. . 2014b. National Archives at New York City; Supreme Court of New York County (251-253); ARC Number: 5324244; ARC Title: Petitions for Naturalization, 1793-1906; Record Group Title: Records of the Immigration and Naturalization Service; Record Group Number: 85. Disponível em: http://search. ancestry.com. Acesso em 08/11/2014. . 2014c. Fourteenth Census of the United States, 1920 (NARA microfilm publication T625, 2076 rolls). Records of the Bureau of the Census, Record Group 29. National Archives, Washington, D.C. For details on the contents of the film numbers, visit the following NARA web page: http:// www.archives.gov/publications/ microfilm-catalogs/census/1920/part07.html. Note: Enumeration Districts
819-839 are on roll 323 (Chicago City). Disponível em: http://search. ancestry.com. Acesso em 09/11/2014. . 2014d. Fourteenth Census of the United States, 1920 (NARA microfilm publication T625, 2076 rolls). Records of the Bureau of the Census, Record Group 29. National Archives, Washington, D.C. For details on the contents of the film numbers, visit the following NARA web page: http:// www.archives.gov/publications/ microfilm-catalogs/census/1920/part07.html. Note: Enumeration Districts 819-839 are on roll 323 (Chicago City). Disponível em: http://search. ancestry.com. Acesso em: 31/10/2014. . 2014e. Disponível em: http:// story.sharing.ancestry.com/ people/7081578?h=61e2db. Acesso em 02/11/2014.

. 2014f. Thirteenth Census of the United States, 1910 (NARA microfilm publication T624, 1,178 rolls). Records of the Bureau of the Census, Record Group 29. National Archives, Washington, D.C. For details on the contents of the film numbers, visit the following NARA web page: http:// www.archives.gov/research/census/ publications-microfilm-catalogscensus/1910/index.html. Disponível em: http://search.ancestry.com. Acesso em 28/10/2014. . 2014g. State population census schedules, 1915. Albany, New York: New York State Archives. Disponível em: http://search.ancestry.com. Acesso em: 28/10/2014. . 2014h. State population census schedules, 1925. Albany, New York: New York State Archives. Disponível em: http://search.ancestry.com. Acesso em: 28/10/2014. 
. 2014i. 1930 United States Federal Census [database on-line]. Provo, UT, USA: Ancestry.com Operations Inc., 2002. Original data: United States of America, Bureau of the Census. Fifteenth Census of the United States, 1930. Washington, D.C.: National Archives and Records Administration, 1930. T626, 2,667 rolls. Disponível em: http://search. ancestry.com. Acesso em: 28/10/2014. . 2014j. Massachusetts, Town and Vital Records, 1620-1988 [database on-line]. Provo, UT, USA: Ancestry. com Operations, Inc., 2011. Original data: Town and City Clerks of Massachusetts. Massachusetts Vital and Town Records. Provo, UT: Holbrook Research Institute (Jay and Delene Holbrook). Disponível em:http://search.ancestry.com. Acesso em: 01/11/2014.

. 20141. Massachusetts, Town and Vital Records, 1620 [database online]. Provo, UT, USA: Ancestry.com Operations, Inc., 2011; Original data: Town and City Clerks of Massachusetts. Massachusetts Vital and Town Records. Provo, UT: Holbrook Research Institute (Jay and Delene Holbrook). Disponível em: http://interactive.ancestry.com. Acesso em: 31/10/2014.

2014m. New York, Passenger Lists, 1820-1957 [database on-line]. Provo, UT, USA: Ancestry.com Operations, Inc., 2010. Disponível em: http:// search.ancestry.com. Acesso em 08/11/2014.

.2014n. 1940 United States Federal Census [database on-line]. Provo, UT, USA: Ancestry.com Operations, Inc., 2012. Original data: United States of America, Bureau of the Census. Sixteenth Census of the United States, 1940. Washington, D.C.: National Archives and Records
Administration, 1940. T627, 4,643 rolls. Disponível em: http://search. ancestry.com. Acesso em 08/11/2014.

BALDUS, Herbert. 1937. "Carta para Heloísa Alberto Torres de 31 de dezembro de 1937". Semear, Museu Nacional, UFRJ. Mimeo.

BENEDICT, Ruth F. 1938. "Carta para o embaixador americano no Brasil em 04 de junho de 1938". Mast, Arquivo História da Ciência, Dossiê William Lipkind. Mimeo.

BOAS, Franz. 1940. Race, language and culture. New York: The Macmillan Company.

. 1942. "Carta para William Lipkind em 25 de maio de 1942". The American Philosophical Society, Franz Boas Paper, USA. Mimeo.

BOHANNAN, Paul; GLAZER, Mark. 1973. High points in anthropology. New York: Knopf.

BOURDIEU, Pierre. 1996a [1994]. Razões práticas - sobre a teoria da ação. Trad. Mariza Corrêa. Campinas: Papirus. . 1996b. "A ilusão biográfica". In: Janaína Amado \& Marieta de Severo Ferreira (orgs.), Usos e abusos da história oral. Rio de Janeiro: Editora da FGV. 183-191

BRASIL. 1938. "Conselho de Fiscalização das Expedições Artísticas e Científicas". Certificado N.1\38 assinado por Paulo Campos Porto em 29 de janeiro de 1938. In: Mast, Arquivo História da Ciência, Dossiê William Lipkind. Mimeo.

. 1939. "Conselho de Fiscalização das Expedições Artísticas e Científicas". Certificado N. 17\39 de 18 de abril de 1939. In: Mast, Arquivo História da Ciência, Dossiê William Lipkind. CARVALHO, Bernardo. 2006. Nove noites. São Paulo: Cia. das Letras.

CITY COLLEGE OF NEW YORK. 1946. William Lipkind, Alumni Register. New York. 
COLUMBIA UNIVERSITY. 2014. Disponível em: http://anthropology. columbia.edu/graduate/ doctoraldissertations. Acesso em 29/10/2014.

CORRÊA, Mariza. 1997. "Dona Heloísa e a pesquisa de campo". Revista de Antropologia, São Paulo, 40(1): 11-54. Disponível em: http://www.scielo.br/scielo. php? script $=$ sci_arttext\&pid $=$ S0034 $77011997000100002 \& \operatorname{lng}=$ en $\& n r m=$ iso. Acesso em 24/10/2014.

; MELlO, Januária (coords). 2008. Querida Heloísa/Dear Heloísa: carta de campo para Heloísa Alberto Torres. Núcleo de Estudos de GêneroPagu. Série Pesquisas. Campinas: Unicamp.

DONAHUE JR., George Rodney. 1982. A contribution to the etnography of the Karajá indians of Central Brazil. Dissertation, Departament of Antropology, University of Virginia.

EHRENREICH, Paul. 1948 [1888]. "As tribos Karajá do Araguaia (Goiás)". Revista do Museu Paulista, 2: 7-135.

ESTERCI, Neide. 1987. Conflito no Araguaia. Peões e posseiros contra a grande empresa. Petrópolis: Vozes.

EWBANK, Cecília de Oliveira. 2015. Documentação museológica da Coleção William Lipkink (19391939). Museu Nacional-UFRJ, Relatório Técnico de Pesquisa, CNPq. Mimeo.

. 2017. A parte que lhe cabe desse patrimônio: o projeto indigenista de Heloísa Alberto Torres para o Museu Nacional (1938-1955). Dissertação de Mestrado, Programa de Pósgraduação em História, Universidade Federal de Santa Catarina.

EWBANK, Cecilia de Oliveira; GRIPP, Maria Pierro. 2016. Adendo aos Relatórios Técnicos de Pesquisa CNPq de Cecilia de Oliveira Ewbank (2015) e Maria Pierro Gripp (2016) sobre a documentação museológica da Coleção William Lipkind (19381939), Museu Nacional-UFRJ. Mimeo.

FABIAN, Johannes. 2014. Time and the other: how anthropology makes its objects. Ney York: Columbia University Press.

FAULHABER, Priscila.2005. O etnógrafo e seus "outros": informantes ou detentores de conhecimento especializado? Revista Estudos Históricos, Rio de Janeiro, v. 2, n. 36, p. 111-130, jan.

GRUPIONI, Luís Donisete Benzi. 1998. Coleções e expedições vigiadas - os etnólogos no conselho de fiscalização das expedições artísticas e científicas do Brasil. São Paulo: Editora Hucitecx/Anpocs.

KRAUSE, Fritz. 1940-1943 [1904]. "Nos Sertões do Brasil". Revista do Arquivo Municipal, 66-91.

LANDES, Ruth Schlossberg. 1947. The city of women. Introduction by Sally Cole. New York: Macmillan. Reprinted in 1994 by University of New Mexico Press.

LE GOFF, Jacques. 1991. “Uma entrevista com Jacques Le Goff" (realizada por Monique Augras). Revista Estudos Históricos, 4(8):262-270.

LIMA FILHO, Manuel Ferreira. 1994. Hetohoky: um rito karajá. Goiânia: Editora da UCF. . et al. 2011a. Bonecas karajá: arte, memória e identidade indígena no Araguaia - dossiê descritivo do modo de fazer ritxoko. Goiânia: Universidade Federal de Goiás Museu Antropológico. et al. 2011b. Ritxoko. Documentário, 45 minutos. Goiânia: Iphan/UFG. et al. 2011c. Documentário, 18 minutos. Goiânia: Iphan/UFG.

LIPKIND, Maria Cimino. Carta de 24 de abril de 1938. Aldeia de Fontoura, Ilha do Bananal. 
LIPKIND, William. 1937. Carta de William Lipkind para Ruth Benedict em 01 de maio de 1939. Ruth Fulton Benedict papers, Folder 31.11, Vassar College Archives Special Collections. . 1938a. Carta de William Lipkind para Franz Boas em 04 de maio de 1938. In: American Philosophical Society, Franz Boas Collection, USA. . 1938b. Carta de William Lipkind para Franz Boas em 06 de maio de 1938. In: American Philosophical Society, Franz Boas Collection, USA. . 1938c. Carta de William Lipkind para Heloísa Alberto Torres. Dossiê Lipkind, CCHAT, Itaboraí, Rio de Janeiro.

. 1939a. Carta de William Lipkind para Ruth Benedict em 01 de maio 1939. Dossiê Lipkind, CCHAT, Itaboraí, Rio de Janeiro.

. 1939b. Carta de William Lipkind para MRs. Urbach em 30 de maio de 1939. In: American Philosophical Society, Franz Boas Collection, USA. . 1939c. Carta de William Lipkind para Heloísa Alberto Torrers em 02 de setembro de 1939. Dossiê Lipkind, CCHAT, Itaboraí, Rio de Janeiro.

. 1940. "Carajá Cosmography". The Journal of American Folklore, LIII(210) :248-251.

. 1942a. Carta de William Lipkind para Franz Boas em 07 de fevereiro de 1942. In: American Philosophical Society, Franz Boas Collection, USA. - 1942b. Carta de Wilb Boas Collection, USA.

. 1943a. Carta de William Lipkind para Ruth Benedict em 05 de fevereiro de 1943. In: Ruth Fulton Benedict Papers, Folder 31.12, Vassar College Archives and Special Collections, USA.

. 1945. Winnabago Grammar. New

York: King's Crown Press.

. 1948. "The Carajá". In: Julian
Steward (org.), Handbook of South American indians: the tropical forest tribes. Bureau of American Ethnology Bulletins. pp. 179-191.

MONTAGNER, Miguel Ângelo. 2007. "Trajetória e biografias: notas para uma análise bourdieusiana". Sociologia, 9(17):240-264.

MOURA, Margarida Maria. 2006. "Franz Boas: a antropologia cultural no seu nascimento". Revista da USP, São Paulo, n. 69:123-134, mar.-maio.

NEW YORK TIMES. 1974. "William Lipkind, Anthropologist - Expert on Brazil Indians and A Children's Author Dies". New York, October 3.

MATO GROSSO. 1938. Diário Oficial do Estado do Mato Grosso de 29 de maio de 1938. In: Mast, Arquivo História da Ciência, Dossiê William Lipkind. Mimeo.

MAYBURY-LEWIS， David. 1979. Dialectial societies: the Gê and Bororo of Central Brazil. Cambridge: Harvad Uniersity Press.

O GLOBO. 1939. "Pajé dos Javahés, um norte-americano!". 15 de novembro de 1939, Rio de Janeiro.

OLIVEIRA, João Pacheco de. 2007. $O$ retrato de um menino Bororo: narrativas sobre o destino dos índios e o horizonte político dos museus, séculos XIX e XXI. Tempo, Niterói, v. 12, n. 23, p. 73-99, 2007. Available from < http://www.scielo.br/scielo. php? script $=$ sci_arttext $\&$ pid $=$ S141377042007000200006\&lng $=$ en\&nrm =iso $>$. access on 17 Dec. 2017. http://dx.doi.org/10.1590/S141377042007000200006.

OLIVEIRA，João Pacheco de, 2013. "Etnografia enquanto compartilhamento e comunicação: desafios atuais às representações coloniais da antropologia". In: Bela Grammar Feldman-Bianco (org.), Desafios da antropologia brasileira. Brasília: ABA. Pgs. 47-74. 
PEREIRA, Edmundo; LIMA FILHO, Manuel F. 2016. "Desnaturalizando assimetrias: o 'outro' dentro do Museu". Paper apresentado na XX Associação Portuguesa de Antropologia, Coimbra. Mimeo.

PETESCH, Nathalie. 1993. "A trilogia karajá: sua posição intermediária no continuum Jê-Tupi". In: Eduardo Viveiros de Castro \& Manuela Carneiro da Cunha (orgs.), Amazônia: etnologia e história indígena. São Paulo: USP-NHII/Fapesp. Pgs 365384.

. 1996. La pirogue de sable modes de représentation et d'organisation d'une société du fleuve: les Karajá de l'Araguaia (Brésil Central). Tese de Doutorado em Antropologia, Université Paris X.

PRICE, David H. 2008. Anthropological intelligence: the deployment and neglect of American anthropology in the Second World War. Durham: Duke University Press.

RIBEIRO, Berta Gleizer. 1988. Dicionário do artesanato indígena. Belo Horizonte/Itatiaia/São Paulo: EdUSP. RODRIGUES, Patrícia de Mendonça. 1993. O povo do meio: tempo, cosmo e gênero entre os Javaé da ilha do Bananal. Dissertação de Mestrado, Universidade de Brasília. . 2008. A caminhada de Tanyxiwe: uma teoria javaé da História. Tese de Doutorado, Universidade de Chicago.

SAHLINS, Marshall. 2004. Metáforas históricas e realidades míticas. Estrutura nos primórdios da história do reino das Ilhas Sandwich. Trad. Fraya Freshe. Rio de Janeiro: Jorde Zahar Ed.

SAID, Edward. 2007. Orientalismo. O Oriente como invenção do Ocidente. São Paulo: Companhia das Letras.

SMITHSONIAN INSTITUTION. 2017.
Archives of American Art. Alice Yamin papers, 1927-1998; Series 4: Photographs, 1923-1978. Box 2, Folder 79, Photographs of Family Members and Friends, including Aaron Siskind, 1923-1952, undated. STOCKING JR., George W. 1982. "On the limits of presentism and historicism in the historiography of the behavioral sciences". In: Race, culture and evolution - essays in the history of anthropology. Chicago: The University of Chicago Press. Pags 1-12.

. 2004. "Antropologia de Chicago: a fundação de um departamento independente - 1923-1929". Trad. Plinio Dentzien. In: Fernanda A. Peixoto; Heloísa Pontes \& Lilia M. Schwarcz (orgs.), Antropologias, histórias, experiências. Belo Horizonte: Editora da UFMG. Pag. 15-60.

TAVEIRA, Edna Luisa de Melo. 2013. Etnografia da cesta karajá. Coleções Teses Universitárias 22. Goiânia: Editora da UFG.

THE NEBRASKA STATE JOURNAL (Lincoln, Nebraska). 1940. Where it's year leap every year. Sun, Jul. 28, 1940, p. 40. Disponível em: http//www. newspaper.com/image/42106151. Acesso em 22/10/2014.

TORAL, André Amaral de. 1992. Cosmologia e sociedade karajá. Dissertação de Mestrado em Antropologia, Museu Nacional/ UFRJ. 
TORRES, Heloísa Alberto. 1938. "Despacho à mão na cópia do ofício de 11 de dezembro de 1937 da Embaixada Americana no Brasil". In: Mast, Arquivo História da Ciência, Dossiê William Lipkind. Mimeo.

US EMBASSY. 1937. P\SN\432, (22)\1937 Annexo N. 62. The Embassy of the United States of America. In: Mast, Arquivo História da Ciência, Dossiê William Lipkind.

VASSAR COLLEGE ARCHIVES. 1939. Draeger Shiping Co. INC. em 12 de junho de 1939. In: Ruth Fulton Benedict Papers, Folder 31.11, Special Collections, USA.

WAGLEY, Charles. 1983. Welcome of tears - the Tapirapé indians of Central Brazil. Illinois: Waveland Press, Inc. WAGLEY, Charles. 1939. "Ofício de 08 de março de 1939 para o Conselho de Expedições Científicas e Artísticas do Brasil". In: Mast, Arquivo História da Ciência, Dossiê William Lipkind. 1988. Uma comunidade amazônica: estudo do homem nos trópicos. Trad. Clotide da Silva Costa. Belo Horizonte: Itatiaia.

WANG, Lorain. 2010. "Register to the papers of Ruth Lands". National Anthopological Archives, Smithsonian Institution, Washington. Mimeo. 
COLEÇÃO WILLIAM LIPKIND DO

MUSEU NACIONAL:

TRILHAS ANTROPOLÓGICAS

BRASIL-ESTADOS UNIDOS
THE WILLIAM LIPKIND COLLECTION

OF THE NATIONAL MUSEUM:

TRACING ANTHROPOLOGICAL

ROUTES BETWEEN BRAZIL AND THE UNITED STATES

\section{Resumo}

O artigo versa sobre a construção da "Coleção Karajá William Lipkind" composta por 527 (454 localizados) artefatos do acervo do Setor de Etnologia e Etnografia do Museu Nacional, realizada pelo antropólogo estadunidense William Lipkind. Filho de emigrantes judeusrussos, Lipkind chega ao Brasil num período de eminência da Segunda Guerra Mundial, quando permanece por 14 meses, de 1938 a 1939, entre os Karajá do vale do Araguaia. Sua pesquisa é mediada pela diretora do Museu Nacional, Heloísa Alberto Torres que recebe igualmente outros estudantes da Universidade de Columbia, como Buell Quain, Ruth Landes e Charles Wagley. O estudo dos itinerários da coleção de William Lipkind, entre outros atores e instituições no Brasil e nos Estados Unidos, traz conhecimento novo a respeito da qualificação da própria coleção, da história da antropologia no Brasil e nos Estados Unidos.

Palavras-chave: Coleção William Lipkind, Karajá, História da Antropologia.

\section{Abstract}

This article examines the "Karajá Collection of William Lipkind" which consists of 527 artefacts (454 of which have been located) collected by the North American anthropologist William Lipkind, belonging to the Ethnology and Ethnography Sector of the National Museum in Rio de Janeiro (Museu Nacional, RJ). The son of Jewish-Russian emigrants, Lipkind arrived in Brazil close to the start of World War II and lived for 14 months, from 1938 to 1939, with the Karajá of the Araguaia valley. His research was facilitated by the director of the National Museum, Heloísa Alberto Torres, who also facilitated the work of other students from Columbia University, including Buell Quain, Ruth Landes and Charles Wagley. The study of the collection's itineraries, and the relationships between William Lipkind and other actors and institutions in Brazil and the United States, affords new knowledge about the collection itself, the history of anthropology in Brazil and the United States.

Key words: William Lipkind Collection, Karajá, History of Anthropology. 
COLECCIÓN WILLIAM LIPKIND DEL MUSEO NACIONAL: SENDEROS ANTROPOLÓGICOS BRASILESTADOS UNIDOS

\section{Resumen}

El artículo versa sobre la construcción de la "Colección Karajá William Lipkind" compuesta por 527 (454 localizados) artefactos del acervo del Sector de Etnología y Etnografía del Museo $\mathrm{Nacional}_{\iota}$ realizada por el antropólogo estadunidense William Lipkind. Hijo de inmigrantes judíos-rusos, Lipkind llega al Brasil en un período previo a la Segunda Guerra Mundial ${ }_{L}$ cuando permanece por
14 meses $_{\perp}$ de 1938 a 1939 entre los Karajá del valle del Araguaia. Su investigaciónes mediada por la directora del Museo Nacional, Heloísa Alberto Torres que recibe igualmente otros estudiantes de la Universidad de Columbia ${ }_{\perp}$ como Buell Quain, Ruth Landes y Charles Wagley. El estudio de los itinerarios de la colección de William Lipkind ${ }_{\iota}$ entre otros actores e instituciones en Brasil y los Estados Unidos ${ }_{\perp}$ proporciona un nuevo conocimiento en relación a la calidad de la propia colección y la historia de la antropología en Brasil y Estados Unidos. Palabras clave: Colección William Lipkind, Karajá, Historia de la Antropología. 